Key Words:

Rotary Filter

Filtration

Hanford

\title{
Testing of a Rotary Microfilter to Support Hanford Applications
}

\author{
M. R. Poirier \\ D. T. Herman \\ D. B. Stefanko \\ S. D. Fink
}

June 26, 2008 


\section{DISCLAIMER}

This report was prepared for the United States Department of Energy under Contract No. DE-AC09-96SR18500 and is an account of work performed under that contract. Reference herein to any specific commercial product, or process, does not necessarily constitute or imply endorsement, recommendation, or favoring of same by Washington Savannah River Company or by the United States Government or any agency thereof. The views and opinions of the authors expressed herein do not necessarily state or reflect those of the United States Government or any agency thereof.

Printed in the United States of America

Prepared For

U.S. Department of Energy 
WSRC-STI-2008-00339

Revision 0

\section{Reviews and Approvals}

\section{Authors}

M. R. Poirier, SRNL, Separations Science Programs

Date

D. T. Herman, SRNL, Separations Science Programs

Date

D.B. Stefanko, SRNL, Advanced Characterization \& Process Chemistry Date

\section{Design Check}

C. A. Nash, SRNL, Separations Science Programs

Date

\section{Customer:}

D. Hamilton, CH2MHill

Date

Management

S. D. Fink, Manager, SRNL, Separations Science Programs

Date

J. C. Griffin, Manager, SRNL E\&CPT Research Programs

Date 
WSRC-STI-2008-00339

Revision 0

\section{SUMMARY}

Savannah River National Laboratory (SRNL) researchers are investigating and developing a rotary microfilter for solid-liquid separation applications at the Savannah River Site (SRS).

Because of the success of that work, the Hanford Site is evaluating the use of the rotary microfilter for its Supplemental Pretreatment process. The authors performed rotary filter testing with a full-scale, 25-disk unit with $0.5 \mu$ filter media manufactured by Pall Corporation using a Hanford AN-105 simulant at solids loadings of 0.06, 0.29, and 1.29 wt \%.

The conclusions from this testing follow.

- The filter flux at $0.06 \mathrm{wt} \%$ solids reached a near constant value at an average of $0.26 \mathrm{gpm} / \mathrm{ft}^{2}$ (6.25 gpm total).

- The filter flux at $0.29 \mathrm{wt} \%$ solids reached a near constant value at an average of $0.17 \mathrm{gpm} / \mathrm{ft}^{2}$ (4 gpm total).

- The filter flux at $1.29 \mathrm{wt} \%$ solids reached a near constant value at an average of $0.10 \mathrm{gpm} / \mathrm{ft}^{2}$ (2.4 gpm total).

- Because of differences in solids loadings, a direct comparison between crossflow filter flux and rotary filter flux is not possible. The data show the rotary filter produces a higher flux than the crossflow filter, but the improvement is not as large as seen in previous testing.

- Filtrate turbidity measured $<4$ NTU in all samples collected.

- During production, the filter should be rinsed with filtrate or dilute caustic and drained prior to an extended shutdown to prevent the formation of a layer of settled solids on top of the filter disks.

- Inspection of the seal faces after 140 hours of operation showed an expected amount of initial wear, no passing of process fluid through the seal faces, and very little change in the air channeling grooves on the stationary face.

- $\quad$ Some polishing was observed at the bottom of the shaft bushing. The authors recommend improving the shaft bushing by holding it in place with a locking ring and incorporated grooves to provide additional cooling.

- The authors recommend that CH2MHill Hanford test other pore size media to determine the optimum pore size for Hanford waste.

\section{INTRODUCTION}

SRNL researchers identified and tested the rotary microfilter as a technology to increase solidliquid separation throughput. ${ }^{1,2,3,4}$ The testing showed significant improvement in filter flux with the rotary microfilter over the baseline crossflow filter (i.e., 2.5 - 6.5X during the scoping tests, as much as $10 \mathrm{X}$ in actual waste tests, and approximately $2 \mathrm{X}$ in pilot-scale tests).

SRNL received funding from DOE EM-21, Office of Waste Processing (formerly Office of Cleanup Technologies), to develop the rotary microfilter for high level radioactive service. The work focused on evaluating alternative rotary microfilter vendors, redesigning the equipment for radioactive service, engineering studies to evaluate the risks, determining downstream impacts, assessing costs and benefits of deploying this technology, performing actual waste and pilot- 
scale testing of the technology, and evaluating alternative filter media. The work led to the decision to design, fabricate and perform testing on a full-scale rotary microfilter for potential SRS Tank Farm applications.

SRNL performed the following work to evaluate the rotary microfilter. They demonstrated flushing of the filter housing and effective removal of soluble and insoluble contaminants. They tested the rotary microfilter performance with simulated small column ion exchange feed and observed $\sim 6 \mathrm{X}$ improvement in filter flux of a crossflow filter with similar feed. They conducted simulated sludge washing and found the rotary filter unit behaved as a continuous stirred tank reactor. They concentrated the feed to $20 \mathrm{wt} \%$ solids, and the filter flux was $\sim 6 \mathrm{X}$ the flux measured with a crossflow filter at similar solids loadings. ${ }^{5}$

Because of the success of that testing, the Hanford Site is evaluating the use of the rotary microfilter for its Supplemental Pretreatment process. ${ }^{6}$ The authors received funding from DOE EM-21 to continue the development of the rotary microfilter and to evaluate its suitability for being the solid-liquid separation technology for Supplemental Pretreatment. ${ }^{7,8}$

The SpinTek high shear rotary filter used in this testing has 25 filter disks covered with $0.5 \mu$ pore size (nominal) sheet membranes ( 0.007 inch thick) manufactured by Pall Corporation. The filter area of each disk is $0.96 \mathrm{ft}^{2}$. The disks are physically mounted on and are hydraulically connected to a common hollow rotating shaft. The entire stack of membrane disks is enclosed within a vessel. Feed is fed into the filter vessel through the inlet on the side of the vessel wall. A pressure is set in the tank by restricting the outlet flow typically using a gate valve on the concentrate piping. This applied pressure forces liquid through the filters on the filter disk. Between each disk is a set of baffles or turbulence promoters. These turbulence promoters cause strong currents and eddies at the surface of the membrane inhibiting the formation of a filter cake. Filtrate flows through the media and along a mesh inside the disk into the hollow shaft. The filtrate then flows through the shaft to the rotary joint which allows the spinning shaft to couple to stationary piping. The concentrated slurry exits the vessel through an outlet on the bottom. Figure 1 illustrates the flow paths across the filter disks during filtration.
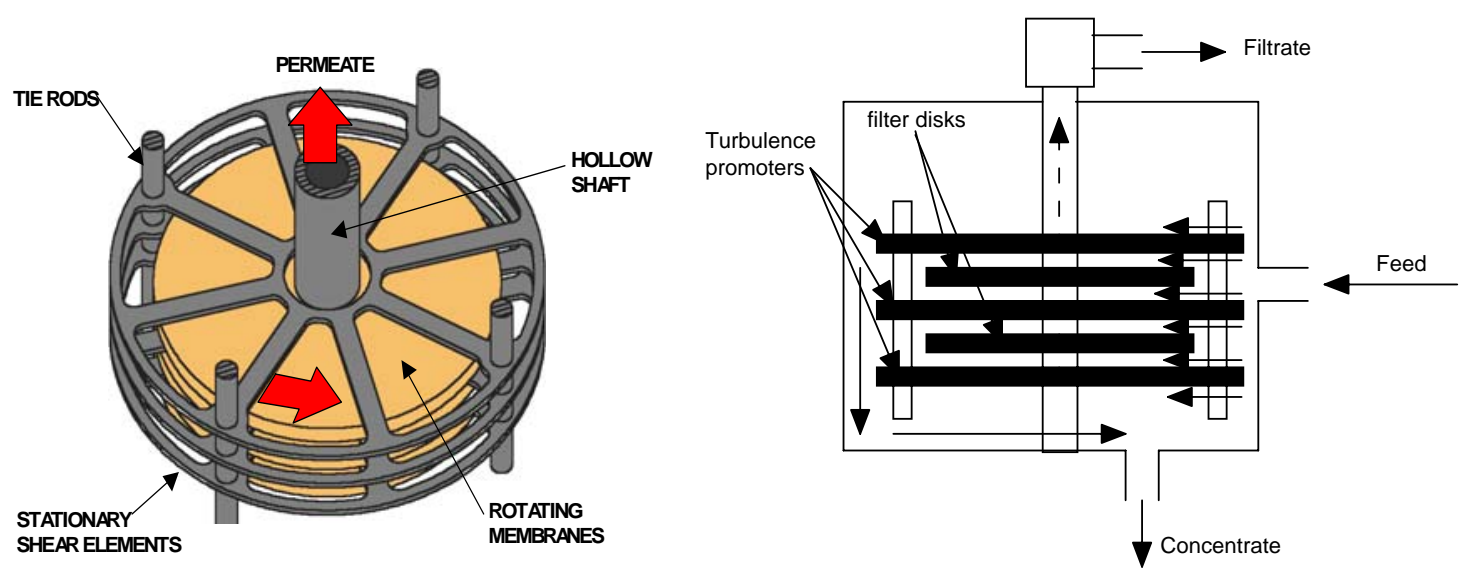

Figure 1. Diagram of Rotary Filter Principle of Operation 
The advantage of the rotary microfilter compared to other membrane processes results from the high shear acting on the boundary layer next to the membrane. This shear greatly reduces fouling of the membrane surface and increases fluid flow through the membrane. Pressure is decoupled from the feed flow rate, allowing more control over the driving force pressure and independent control of the shear applied to the filter cake. This feature allows the direct application of shear force with a magnitude significantly greater than that available in conventional membrane systems. The membranes rotate at a tip speed of $60 \mathrm{ft} / \mathrm{s}$ in close proximity to the turbulence promoters. For comparison, previous cross-flow filter testing used axial velocities ranging from 3 to $25 \mathrm{ft} / \mathrm{s}^{1-4}$. This creates high speed currents and eddies near the membrane surface. These eddies create a great deal of turbulence at the membrane surface decreasing the buildup of filter cake on the membrane. The SpinTek rotary filter unit uses 11-inch diameter disks and typically operates with a rotational speed of $1170 \mathrm{rpm}$.

\section{TESTING}

The authors performed the rotary filter testing with a full-scale, 25-disk unit that had been used in previous testing to support the small column ion exchange and sludge washing applications for SRS. ${ }^{5}$ Figure 2 shows a schematic of the test system.

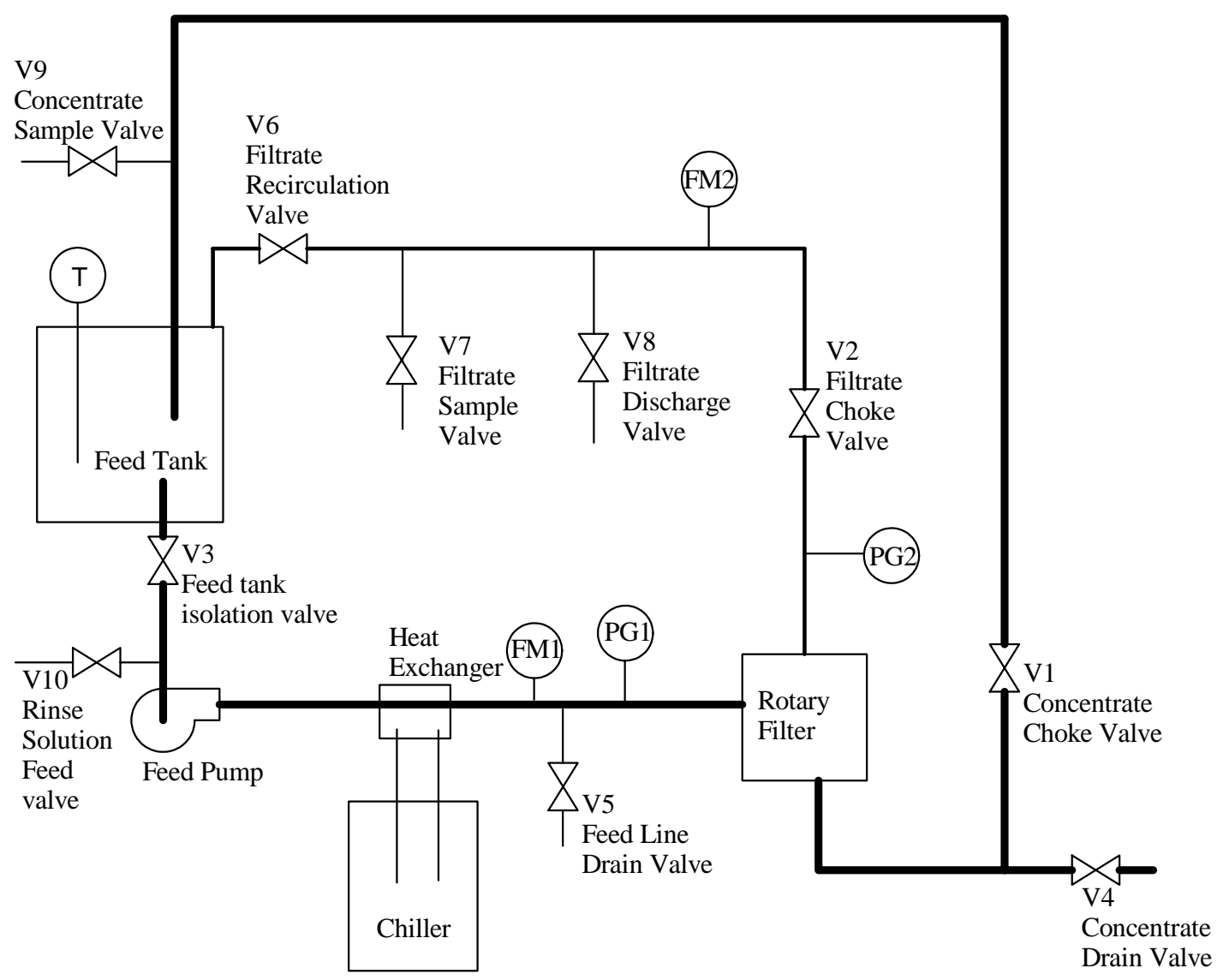

Figure 2. Schematic of Filter Test System 
The pump used in testing was a six stage centrifugal booster pump that had been used in previous testing. ${ }^{5}$ It produced a flow rate of $18-25$ gpm with a feed pressure of $60-100$ psi. The Concentrate and Filtrate Choke valves, V1 and V2 respectively, were PVC gate valves which allowed a fine control of the pressure in the system. All isolation valves, V3 through V9, were PVC ball valves with the exception of V7, the filtrate sample valve, which was stainless steel. Pressure was measured using manual dial pressure gages, which are labeled PG1 and PG2 in Figure 2. Feed and filtrate flow were measured using Fischer Porter Magnetic flow meters and are labeled FM1 and FM2 respectively. The temperature of the process fluid was measured in the feed tank with a Type $\mathrm{K}$ thermocouple, indicated in the sketch as “T”. All data taken during testing was recorded by hand on data sheets. To minimize the amount of feed slurry needed, the concentrate and filtrate streams are recombined in the feed tank. The feed tank is mixed by recirculation of the concentrate and filtrate streams and by a 1 hp agitator.

Prior to the tests conducted here, the filter unit was modified by replacing the silicon carbide/silicon carbide faced John Crane Type 1 mechanical seal with a John Crane Type 28LD air cooled seal. The material of the bottom shaft bushing was changed from graphite to siliconcarbide. To prevent excessive wear on the shaft, an additional silicon carbide sleeve was added so that the contact wear surfaces at the bottom of the shaft are both silicon carbide.

The filter disks used in testing were a set of 25 un-used disks.

Personnel prepared a simulated Hanford AN-105 feed slurry containing 5 M sodium. The recipe is based on the simulant developed in 2000, but it eliminates trace RCRA metals. ${ }^{9}$ Table 1 shows the composition of the supernate and Table 2 shows the solids fractions of the slurry. Personnel prepared 100 gallons of supernate as follows. They added $75.6 \mathrm{~kg}$ of de-ionized water to a tank. Next, they added sodium aluminate, sodium hydroxide (50 wt \% solution), boric acid, calcium nitrate, cesium nitrate, magnesium nitrate, potassium nitrate, zinc nitrate, sodium chloride, sodium fluoride, sodium sulfate, and potassium molybdate. They mixed the solution until all of the compounds dissolved. Next, they added sodium silicate, sodium acetate, sodium formate, sodium glycolate, sodium oxalate, and sodium phosphate, mixing the solution after the addition of each compound. They added an additional $113.4 \mathrm{~kg}$ of de-ionized water, and mixed the solution thoroughly. They added the sodium carbonate, and mixed thoroughly. They added the sodium nitrate and sodium nitrite, and mixed the solution thoroughly. They added an additional $146.7 \mathrm{~kg}$ of de-ionized water, and mixed the solution overnight.

Personnel prepared the solids fraction of the slurry as follows. They procured all of the compounds, except for sodium oxalate, with particle size less than $10 \mu$. The sodium oxalate was not available as less than $10 \mu$, so SRNL personnel ground the sodium oxalate particles using a Union Process SG-1 Attritor Mill and measured the particle size of the product with a scanning electron microscope. The analysis showed the particles to be less than $10 \mu$. They mixed the compounds together in the ratios shown in Table 2. 
WSRC-STI-2008-00339

Revision 0

Table 1. Hanford AN-105 Supernate

\begin{tabular}{ll}
\multicolumn{1}{r}{ Compound } & \multicolumn{1}{c}{ Target Concentration } \\
$\mathrm{NaAlO}_{2}$ & 56.661 \\
$\mathrm{NaOH}$ & 64.461 \\
$\mathrm{H}_{3} \mathrm{BO}_{3}$ & 0.137 \\
$\mathrm{Ca}\left(\mathrm{NO}_{3}\right)_{2} \cdot 4 \mathrm{H}_{2} \mathrm{O}$ & 0.111 \\
$\mathrm{CsNO}$ & 0.114 \\
$\mathrm{Mg}_{3}\left(\mathrm{NO}_{3}\right)_{2} \cdot 6 \mathrm{H}_{2} \mathrm{O}$ & 0.027 \\
$\mathrm{KNO}_{3}$ & 9.030 \\
$\mathrm{Zn}\left(\mathrm{NO}_{3}\right)_{2} \cdot 6 \mathrm{H}_{2} \mathrm{O}$ & 0.022 \\
$\mathrm{NaCl}_{\mathrm{NaF}}$ & 7.039 \\
$\mathrm{Na}_{2} \mathrm{SO}_{4}$ & 0.197 \\
$\mathrm{~K}_{2} \mathrm{MoO}_{4}$ & 0.536 \\
$\mathrm{Na}_{2} \mathrm{SiO}_{3} \cdot 9 \mathrm{H}_{2} \mathrm{O}$ & 0.096 \\
$\mathrm{NaCH}_{3} \mathrm{COO} .3 \mathrm{H}_{2} \mathrm{O}$ & 1.003 \\
$\mathrm{HCOONa}_{\mathrm{HOCH}} \mathrm{COONa}$ & 2.241 \\
$\mathrm{Na}_{2} \mathrm{C}_{2} \mathrm{O} 4$ & 2.044 \\
$\mathrm{Na}_{3} \mathrm{PO}_{4} .12 \mathrm{H}_{2} \mathrm{O}$ & 0.706 \\
$\mathrm{Na}_{2} \mathrm{CO}_{3}$ & 0.436 \\
$\mathrm{NaNO}_{3}$ & 1.072 \\
$\mathrm{NaNO}_{2}$ & 10.405 \\
& 98.500 \\
& 78.211
\end{tabular}

Table 2. Hanford AN-105 Solids

\begin{tabular}{lc} 
Compound & Solids Fraction (\%) \\
\cline { 2 - 2 } $\mathrm{Al}_{2} \mathrm{O}_{3}$ & 9.2 \\
CaOxalate & 5.0 \\
$\mathrm{Cr}_{2} \mathrm{O}_{3}$ & 26.0 \\
$\mathrm{Fe}_{2} \mathrm{O}_{3}$ & 1.1 \\
$\mathrm{MnO}_{2}$ & 0.3 \\
$\mathrm{NaOxalate}$ & 52.5 \\
$\mathrm{NiO}$ & 0.5 \\
$\mathrm{SiO}_{2}$ & 5.4
\end{tabular}

Personnel prepared the slurry as follows. They added 80 gallons of supernate and $226.04 \mathrm{~g}$ of solids to the filter feed tank to produce a $0.06 \mathrm{wt} \%$ solids slurry. They fed the slurry to the filter at a feed flow rate of $\sim 25 \mathrm{gpm}$, a feed pressure of $\sim 70 \mathrm{psi}$, and a feed temperature of $\sim 35{ }^{\circ} \mathrm{C}$. The filtrate pressure was $\sim 30 \mathrm{psi}$, producing a transmembrane pressure of $\sim 40 \mathrm{psi}$. They set the rotor speed to $1170 \mathrm{rpm}$. The filter operated for $\sim 40$ hours on day shift (i.e., $\sim 8$ hours per day, 5 times per week), and personnel recorded the operating parameters and filtrate flow rate during the test. The operating parameters recorded were feed flow rate, filtrate flow rate, feed pressure, concentrate pressure, filtrate pressure, temperature, and rotor speed. Motor current and output power, along with the surface temperatures of the rotary joint and mechanical seal housing were 
measured at random intervals. Appendix A contains the data. They collected filtrate samples twice each day of operation to measure turbidity.

After operating for 40 hours, they added an additional $866.5 \mathrm{~g}$ of solids to the feed tank to produce a $0.29 \mathrm{wt} \%$ solids slurry. They fed the slurry to the filter at a feed flow rate of $\sim 25$ gpm, a feed pressure of $\sim 70 \mathrm{psi}$, and a feed temperature of $\sim 35^{\circ} \mathrm{C}$. The filtrate pressure was $\sim 30$ psi, producing a transmembrane pressure of $\sim 40$ psi. They set the rotor speed to $1170 \mathrm{rpm}$. The filter operated for $\sim 40$ hours on day shift, and personnel recorded the operating parameters and filtrate flow rate during the test. They collected filtrate samples daily to measure turbidity.

After operating for 40 hours, they added an additional $3767.38 \mathrm{~g}$ of solids to the feed tank to produce a $1.29 \mathrm{wt} \%$ solids slurry. They fed the slurry to the filter at a feed flow rate of $\sim 25$ gpm, a feed pressure of $\sim 70$ psi, and a feed temperature of $\sim 35^{\circ} \mathrm{C}$. The filtrate pressure was $\sim 30$ psi, producing a transmembrane pressure of $\sim 40$ psi. They set the rotor speed to $1170 \mathrm{rpm}$. The filter operated for $\sim 40$ hours on day shift, and personnel recorded the operating parameters and filtrate flow rate during the test. They collected filtrate samples daily to measure turbidity.

\section{RESULTS}

\section{Mechanical Performance and Flux}

Figure 3 shows the flux with the $0.06 \mathrm{wt} \%$ slurry. After reaching near constant value, the filter flux averaged $0.26 \mathrm{gpm} / \mathrm{ft}^{2}$ (6.25 gpm total). The filter reached near constant value in approximately 10 hours.

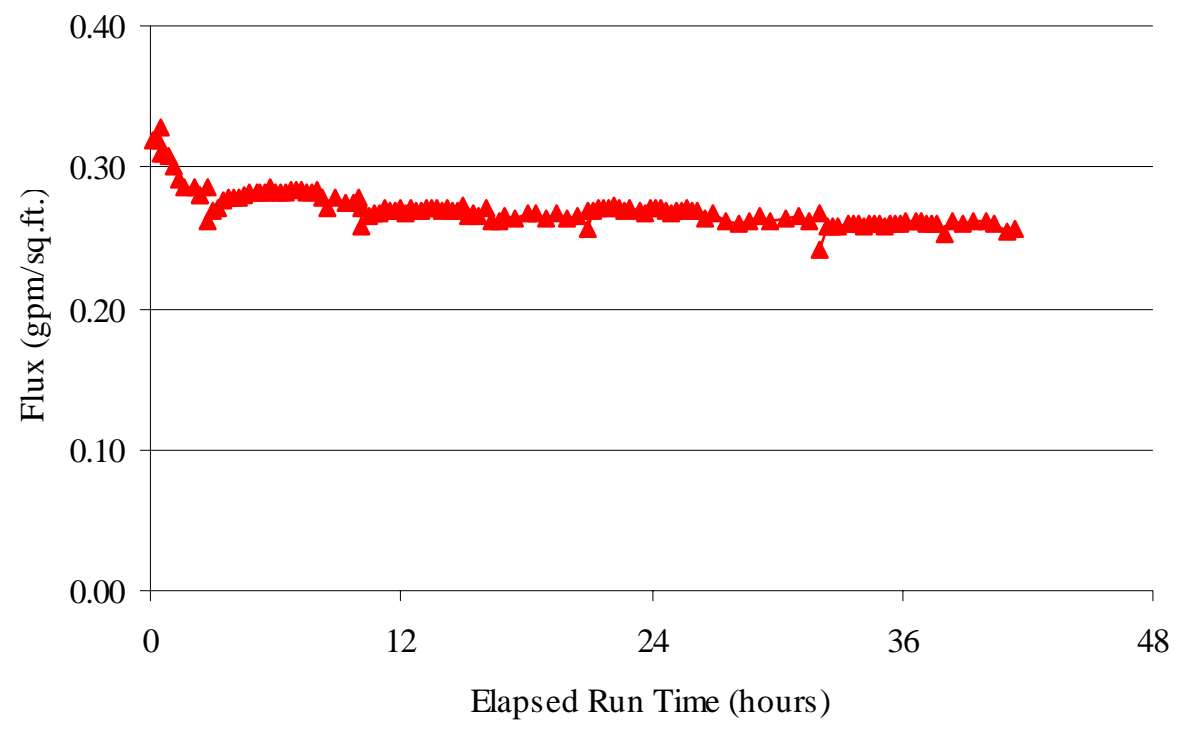

Figure 3 Flux for 0.06 wt\% Insoluble Solids at TMP of 40 psi 
Additional solids were added to the feed to raise the insoluble solids concentration to 0.29 wt $\%$. Figure 4 shows the flux with the 0.29 wt \% slurry. After reaching a near constant value, the filter flux averaged $0.17 \mathrm{gpm} / \mathrm{ft}^{2}$ (4 gpm total). The filter reached a near constant value after approximately 15 hours.

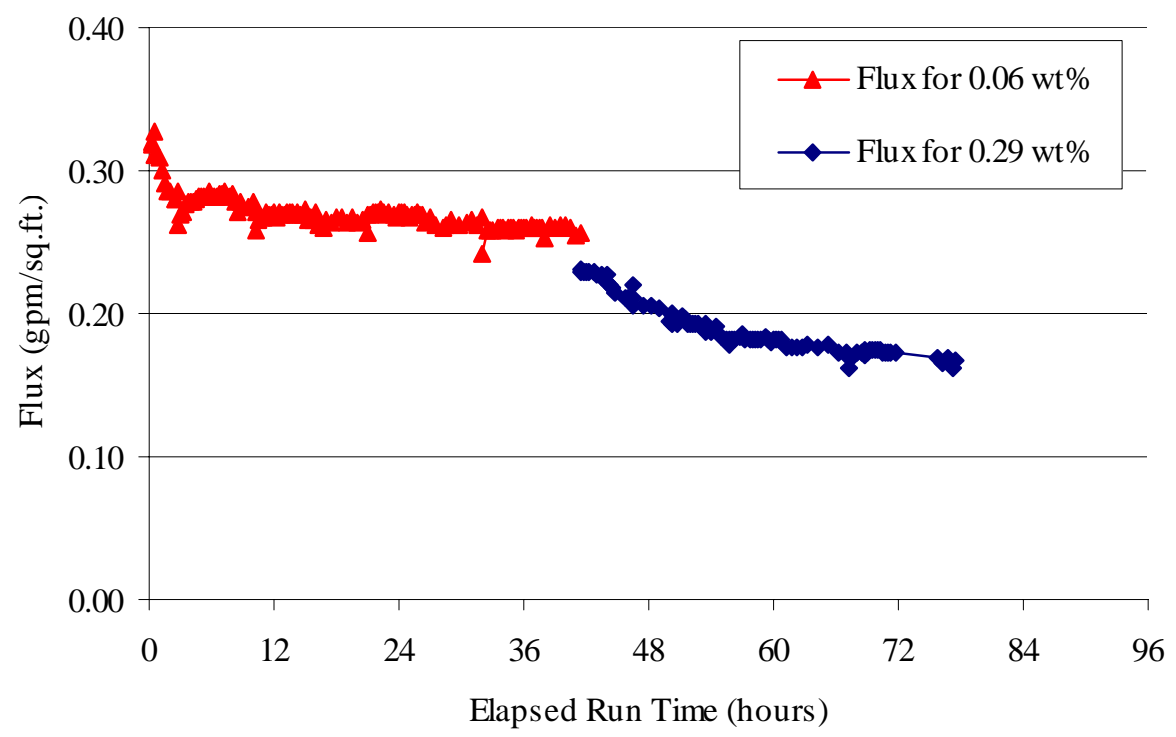

Figure 4 Flux for 0.06 wt \% and 0.29 wt \% Insoluble Solids at TMP of 40 psi

Figure 5 shows the flux with the $1.29 \mathrm{wt} \%$ slurry added. After reaching a near constant value, the filter flux averaged approximately $0.10 \mathrm{gpm} / \mathrm{ft}^{2}$ (2.4 gpm total). The filter flux reached a near constant value after approximately 25 hours.

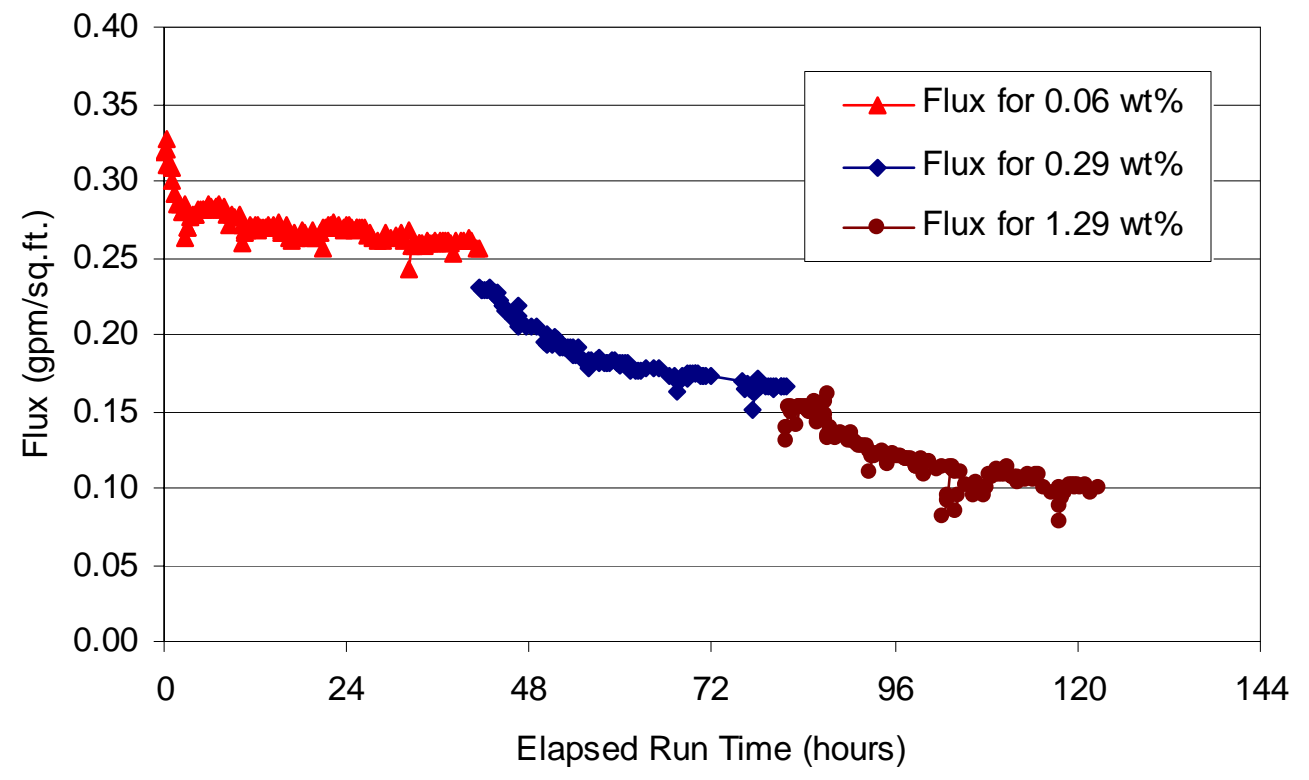

Figure 5 Flux for 0.06 wt \%, 0.29 wt \% and 1.29 wt \% Insoluble Solids at TMP of 40 psi 
Figure 6 compares the flux of the AN-105 simulant to the flux measured during a prior test with simulated SRS sludge. The comparison is made since both sludges contain similar compounds (e.g., metal oxides) and have relatively similar particle size (mean $1-5 \mu$ ). At the start of the testing with $0.06 \mathrm{wt} \%$ solids, the AN-105 simulant had a higher flux than the SRS sludge simulant. When we increased the solids loading to $0.29 \mathrm{wt} \%$, the flux with the AN-105 simulant was initially higher. By the end of that test, the flux was approximately the same for both feed slurries. When we increased the solids loading to $1.29 \mathrm{wt} \%$, the flux with SRS simulant remained approximately the same, while the flux with AN-105 decreased further.

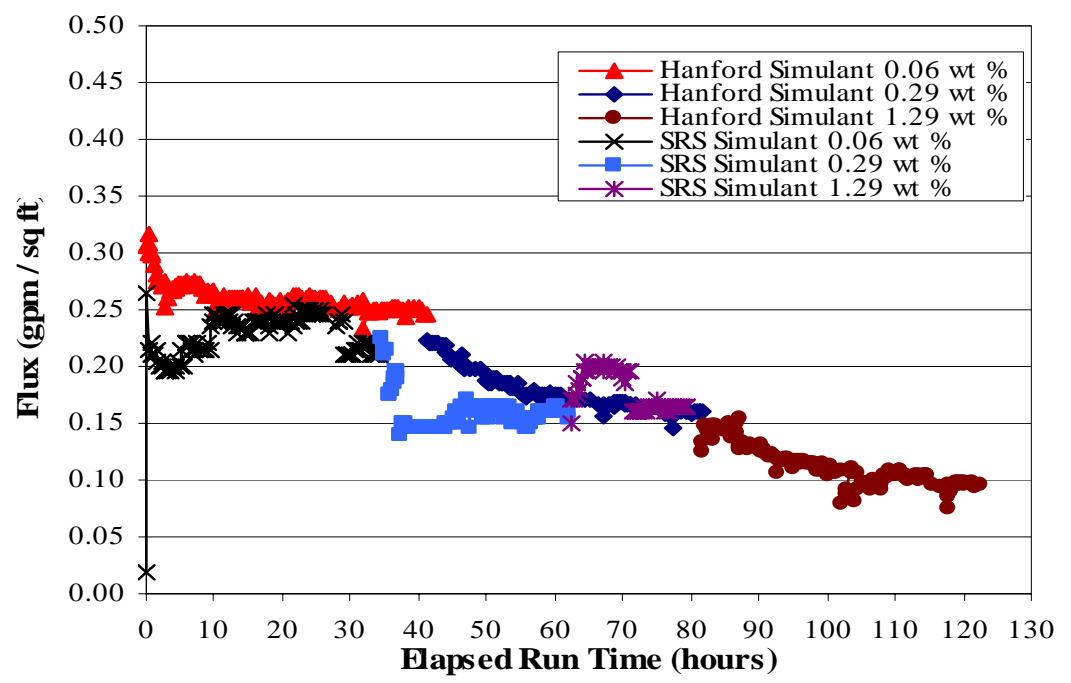

Figure 6 Comparison of SRS and Hanford Simulant Flux Rates

Figure 7 shows a comparison of the $0.06 \mathrm{wt} \%$ insoluble solids loadings for the Hanford simulant and the SRS simulant. ${ }^{5}$

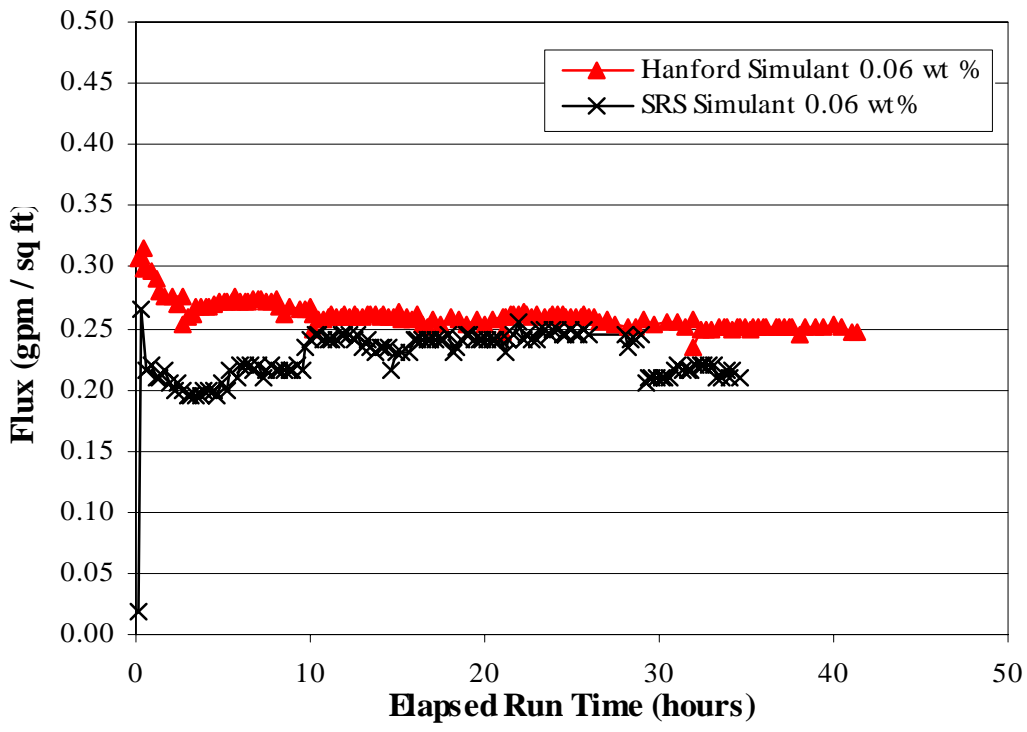

Figure 7 Comparison of Hanford and SRS Simulant Flux Rates at 0.06 wt \% Insoluble Solids 
Figure 8 compares the testing with the AN-105 simulant with the SRS simulant at 0.29 wt \% insoluble solids. ${ }^{5}$ Over the course of testing both simulants reached approximately the same state-state flux of approximately $0.17 \mathrm{gpm}$ per square foot of media. Total filtration rate for the filter unit was approximately $4 \mathrm{gpm}$ at this solids loading.

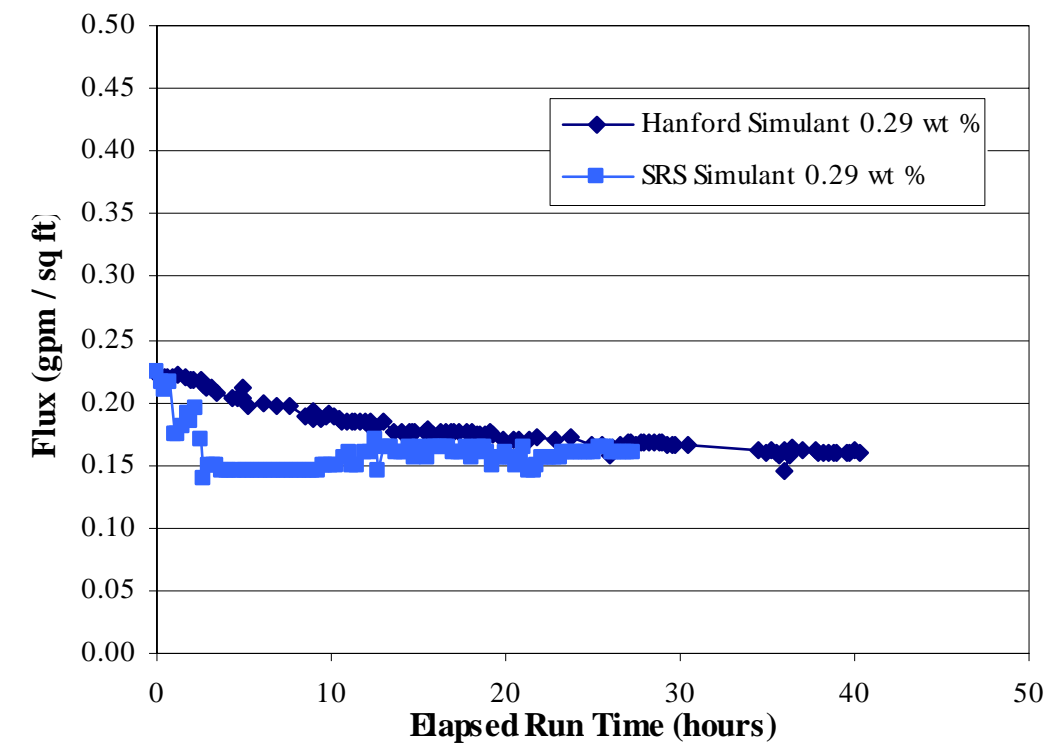

Figure 8 Comparison of Hanford and SRS Simulant Flux Rates at 0.29 wt \% Insoluble Solids 
Figure 9 compares the flux of the AN-105 simulant with the SRS simulant at 1.29 wt \% insoluble solids. ${ }^{5}$ Both simulants had approximately the same starting flux of 0.15 gpm per square foot. The flux with the AN-105 simulant continued to decay until reaching approximately $0.10 \mathrm{gpm}$ per disk or 2.4 gpm of filtrate for the entire unit.

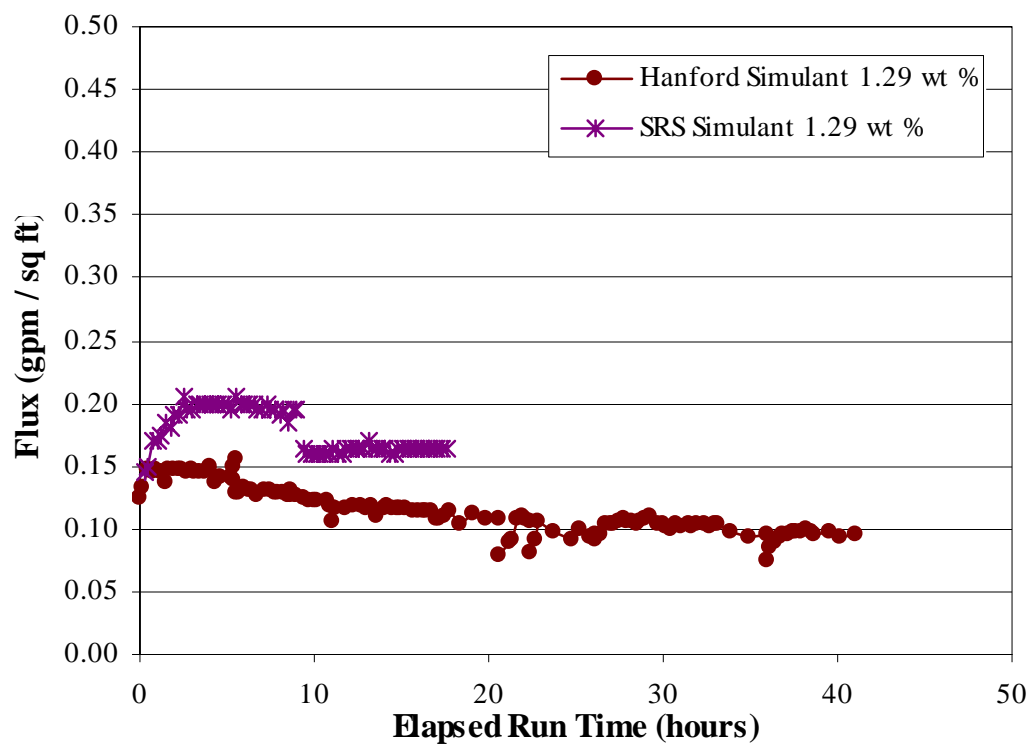

Figure 9 Comparison of Hanford and SRS Simulant Flux Rates at 1.29 wt \% Insoluble Solids 
Figure 10 compares the flux in this test with the flux measured during a crossflow filter test with an AN-105 simulant. ${ }^{10}$ Because the tests used different solids loadings, different filter pore size, and differences in simulant recipe, a direct comparison is not available. Comparing the rotary filter flux at 0.06 wt \% solids with the crossflow filter flux at $0.5 \mathrm{wt} \%$ solids shows the rotary filter flux is $1.8-3.0 \mathrm{X}$ higher. Comparing the rotary filter flux at $0.29 \mathrm{wt} \%$ solids with the crossflow filter flux at $0.5 \mathrm{wt} \%$ solids shows the rotary filter flux is $1.15-2.0 \mathrm{X}$ higher. Comparing the rotary filter flux at $1.29 \mathrm{wt} \%$ solids with the crossflow filter flux at $0.5 \mathrm{wt} \%$ solids shows the rotary filter flux is $0.7-1.25 \mathrm{X}$ of the flux with a crossflow filter.

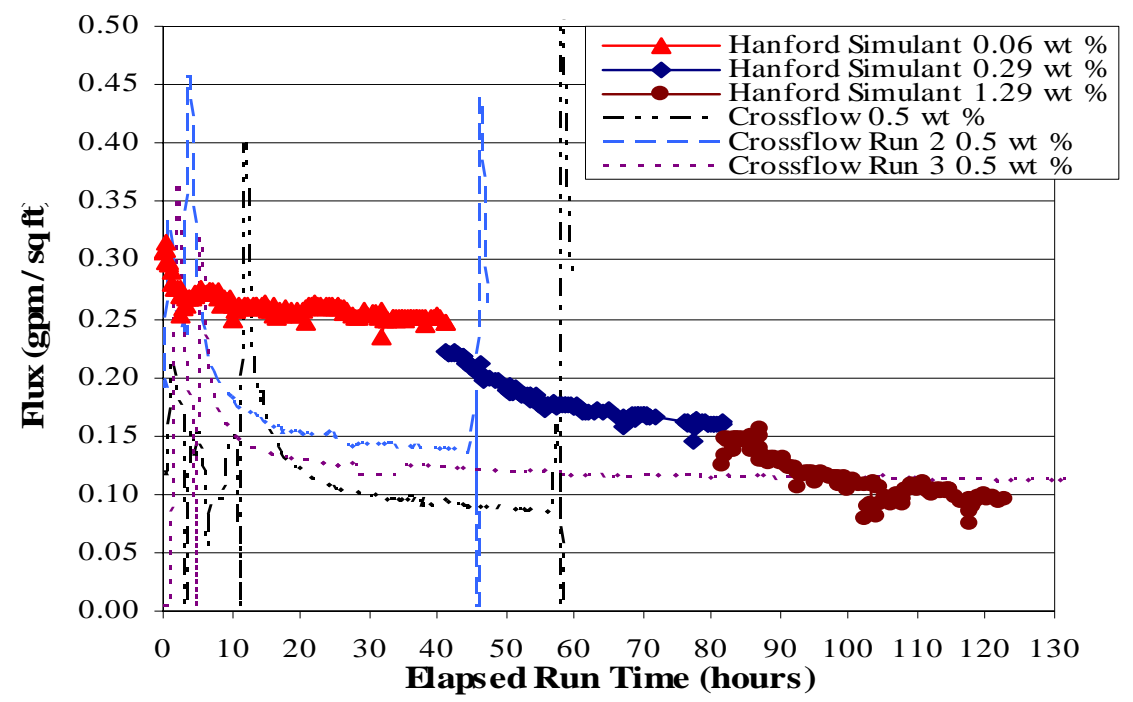

Figure 10 Comparison of Flux with Rotary Filter and Crossflow Filter 
Figure 11 shows the particle size distribution of the solids in the current test and in the rotary filter test using SRS sludge. Particle size was measured with a Microtrac SRA-150. The carrier fluid for the measurement was simulated salt solution (SRS salt solution for SRS sludge and AN105 salt solution for AN-105 solids). The median particle size of the AN-105 solids was $1.49 \mu$. The median particle size of the SRS solids was $3.32 \mu$. In addition, the AN-105 solids had a larger fraction of particles less than $1 \mu$. According to different filtration theories, filter flux increases with increasing particle size. The relationship is described by equation [1]

$$
\mathrm{J}=\mathrm{Kd}_{\mathrm{p}}{ }^{\mathrm{n}}
$$

where $\mathrm{J}$ is filter flux, $\mathrm{K}$ is a constant, $\mathrm{d}_{\mathrm{p}}$ is particle size, and $\mathrm{n}$ is an exponent. Various filtration models have $n$ equal to $4 / 3,2$, and 3 . $^{11}$ In addition, the increase in fine particles $(<1 \mu)$ would provide more particles that could penetrate the filter membrane to foul the filter pores.

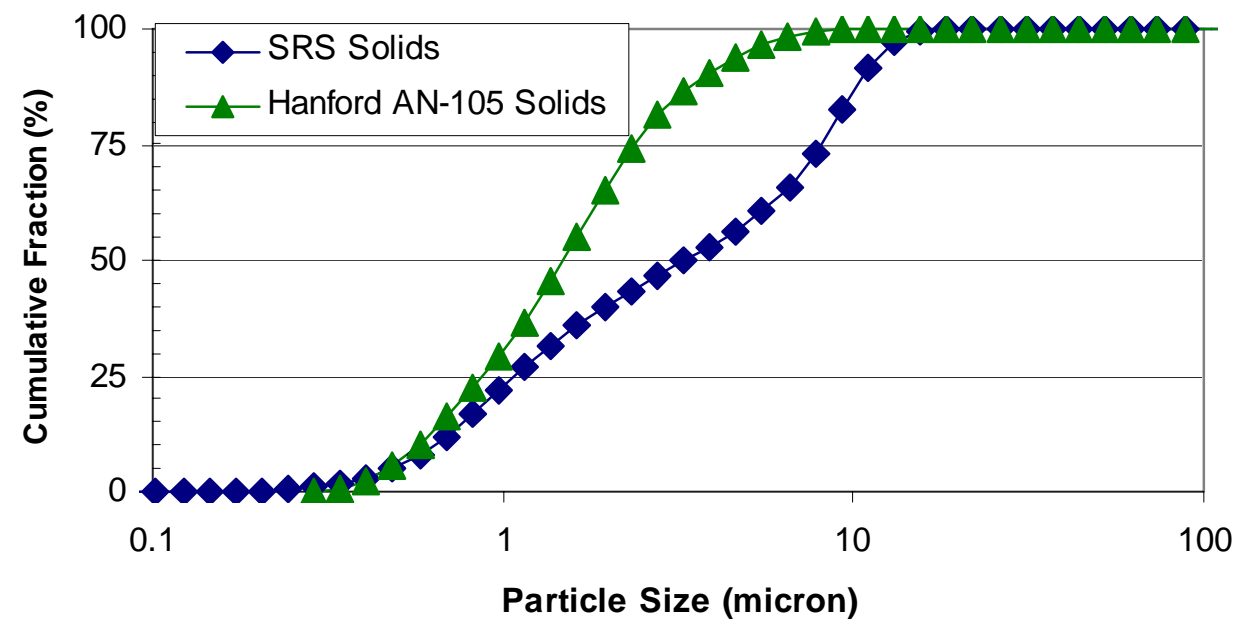

Figure 11. Comparison of Particle Size Data for Hanford and SRS Simulants

Figure 12 shows the particle size of the AN-105 solids from the rotary filter test and the crossflow filter test. The median particle size of the AN-105 solids in the rotary filter test was $1.49 \mu$. The median particle size of the solids during the crossflow filter tests was 2.32 and $2.59 \mu$. As described above, this larger particle size would produce higher filter flux, and may explain why the rotary filter did not show as big of an improvement in filter flux as has been observed in other rotary filter versus crossflow filter tests. In addition, the feed for the rotary filter test had a larger fraction of particles less than $1 \mu$ than the feed for the crossflow filter tests. 


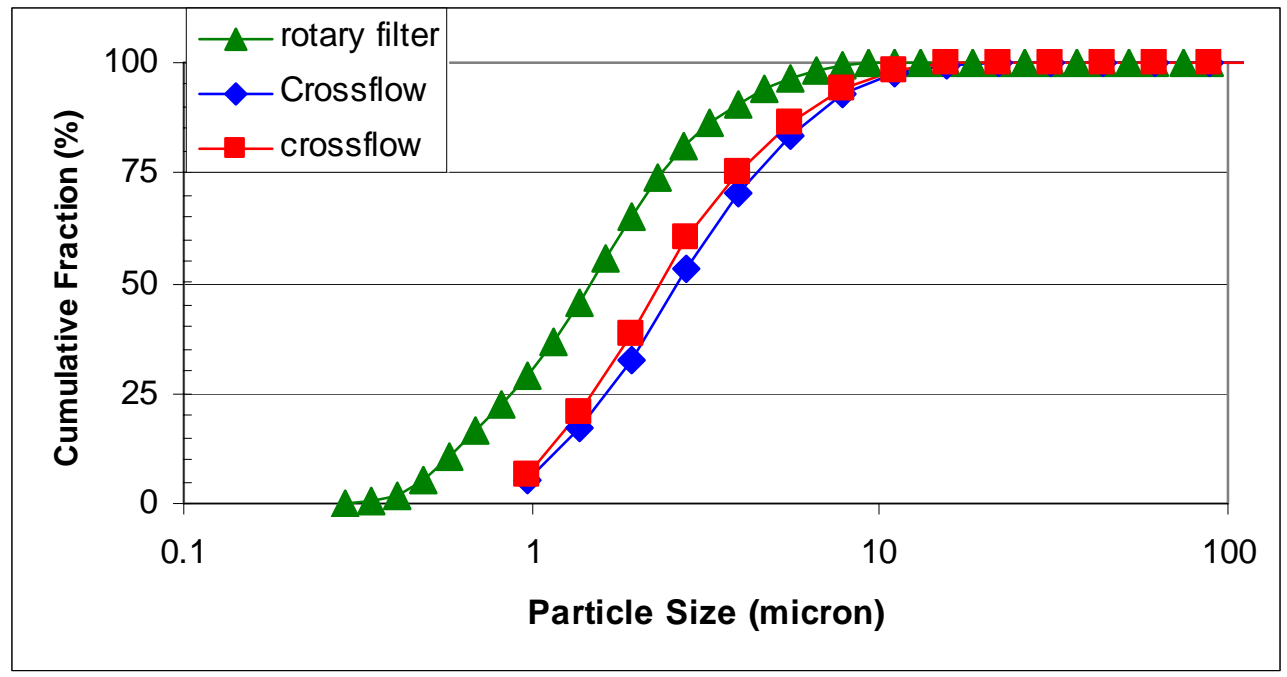

Figure 12. Particle Size Comparison of Hanford Simulant used in Rotary and Crossflow Filters

\section{Filtrate Clarity}

Figure 13 shows the turbidity of the filtrate samples collected. All filtrate samples had turbidity less than 4 NTU.

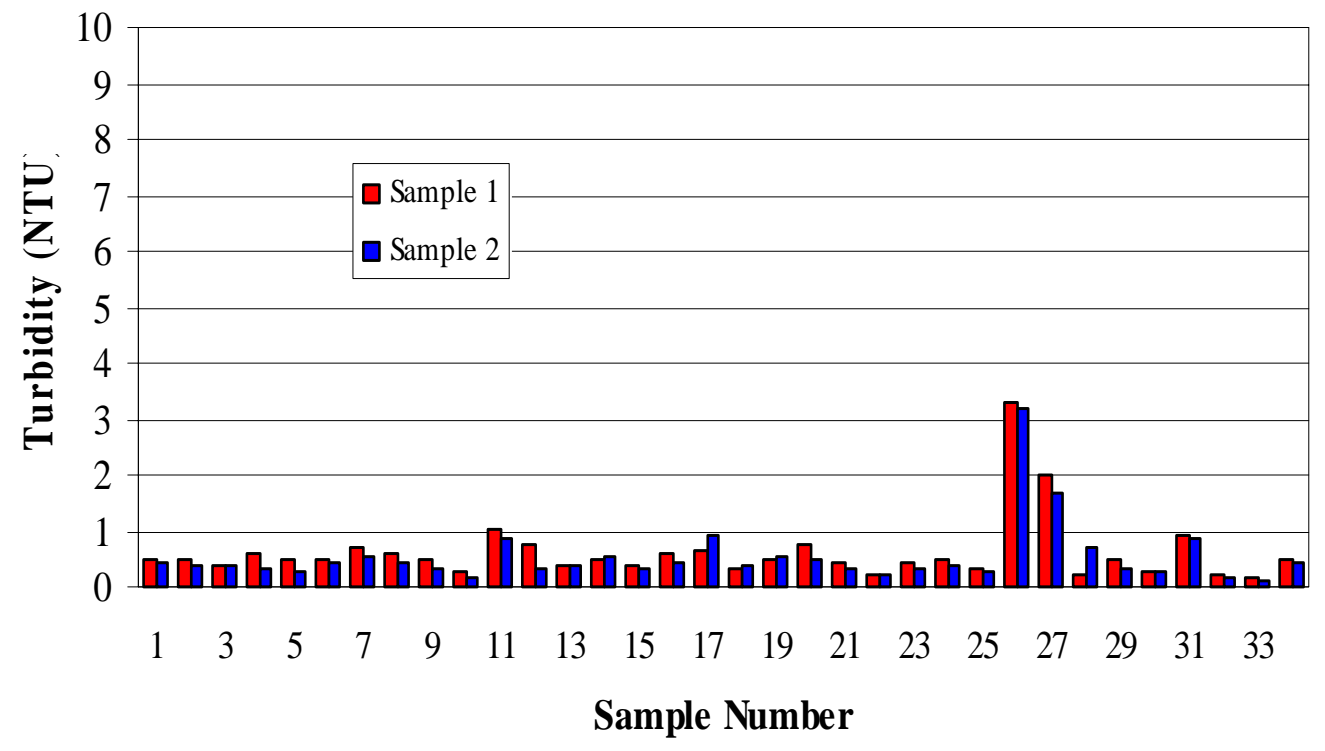

Figure 13. Filtrate Turbidity from Rotary Filter Testing of Hanford Simulant 


\section{Disassembly and Inspection}

After completion of the operational testing, personnel disassembled the filter disk stack. The disk stack was not flushed because the feed pump failed due to the packing of large (up to $2 \mathrm{~cm}$ ) solids in the suction side of the pump (see Appendix B). A significant difference in the filter cake between the top side of the disks and the bottom side was observed. Figure 14 shows the top of a representative filter disk and Figure 15 shows the bottom side of the same filter disk (third from the bottom in the stack). The filter-cake buildup on the top side of the disk is due to the settling of the feed material when operation is complete. During testing, the filter was simply shut down at the end of the day. No draining or flushing was done. Additionally, no attempt was made to clean in the disk in-situ by dropping the TMP while maintaining the rotor speed. In previous testing, this approach was shown to improve filter flux by a small amount. The condition of the filter disks is consistent with previous observations with the top side of the disks showing a greater buildup of solids. This leads to the conclusion that the filter is better at preventing the buildup of filter cake than breaking up a filter cake that has already formed. To prevent the buildup of similar filter-cake in deployment, it is recommended that the filter be drained and flushed with filtrate or dilute caustic after shutdown.

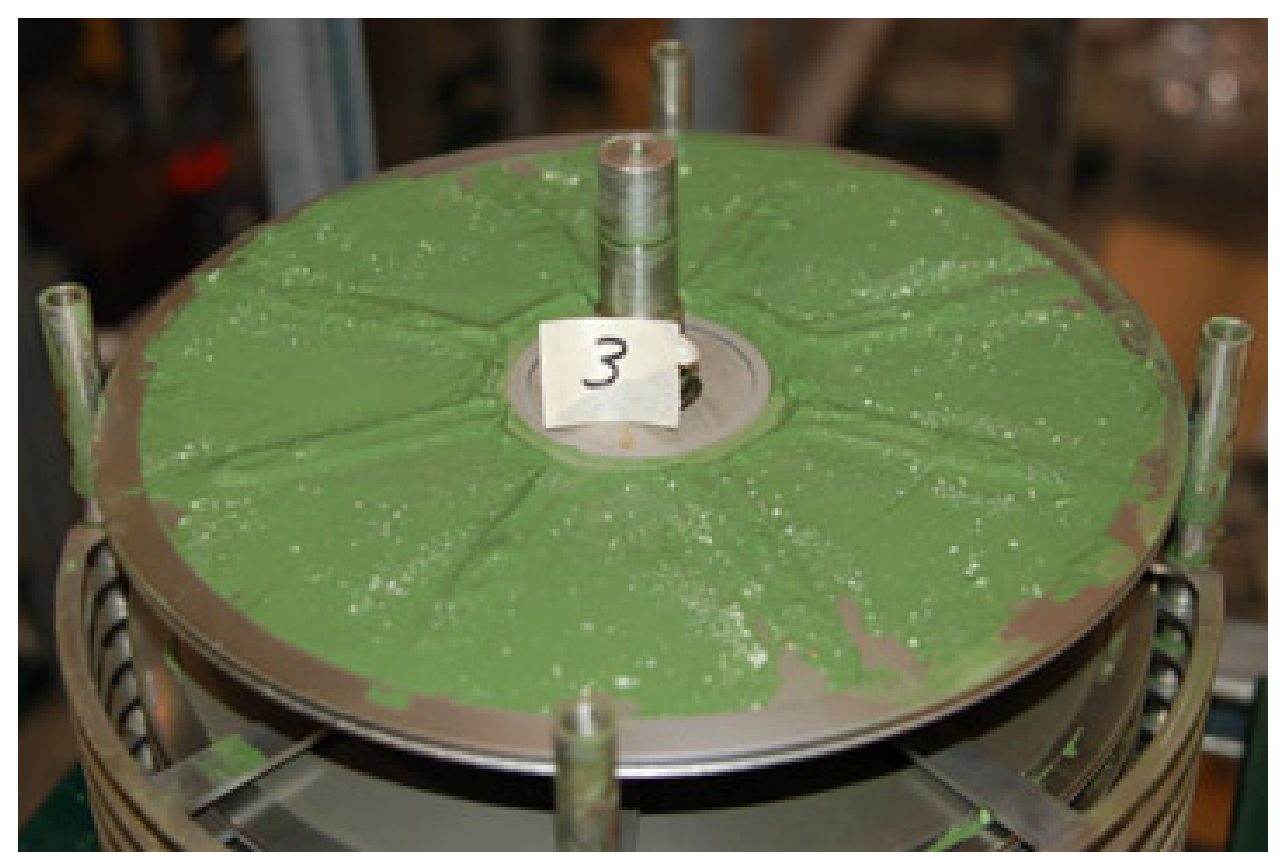

Figure 14 Top Side of Filter Disk 


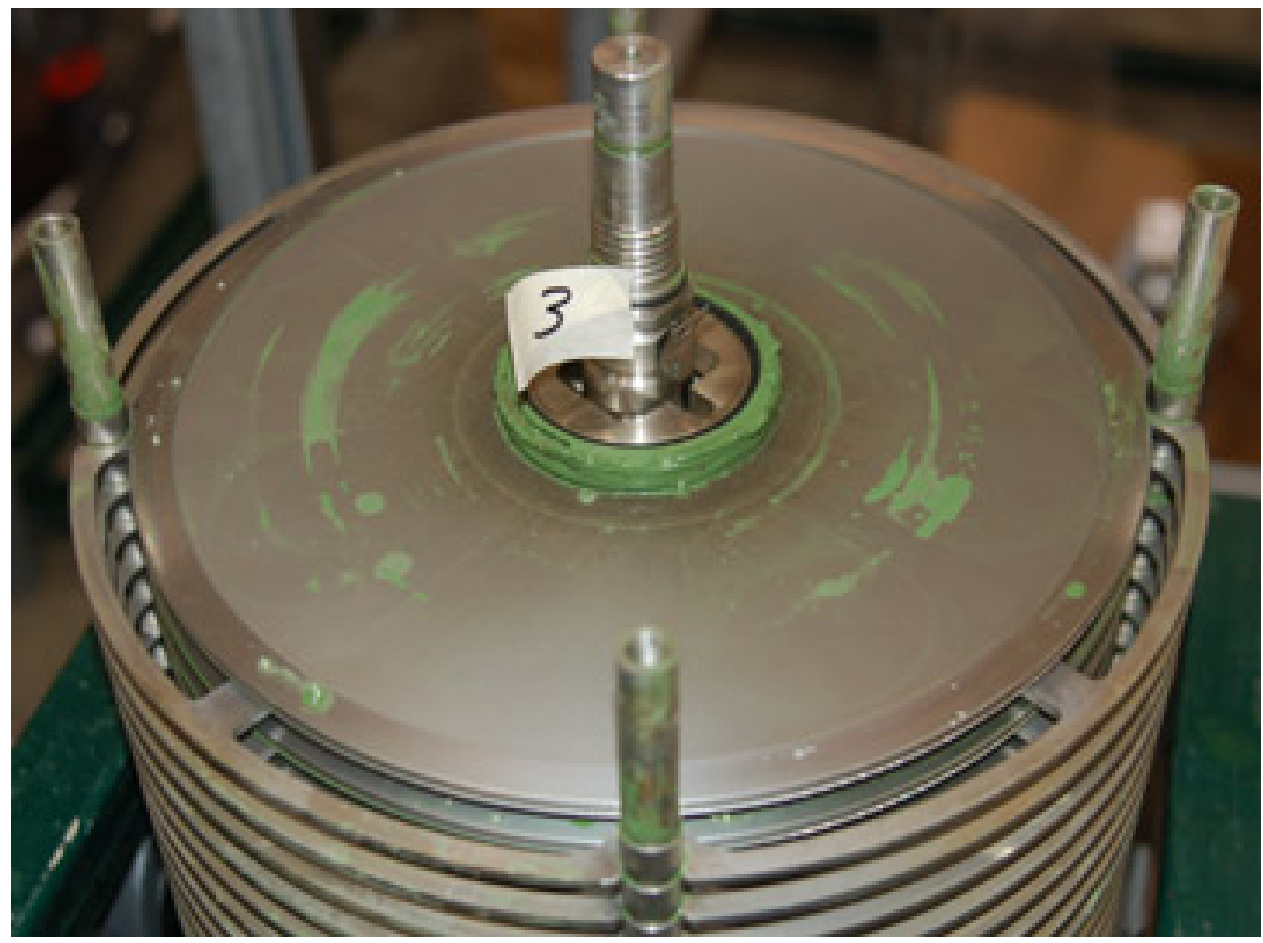

Figure 15 Bottom Side of Filter Disk

\section{Seal Wear Inspection}

After disassembly was completed, the shaft seal was removed and inspected. There was no indication that any of the process fluid passed the seal. Figure 16 shows the seal rotor after the first 20 hours and 44 minutes (i.e., left photo) of operation and then after 143 hours and 28 minutes (i.e., right photo) of operation

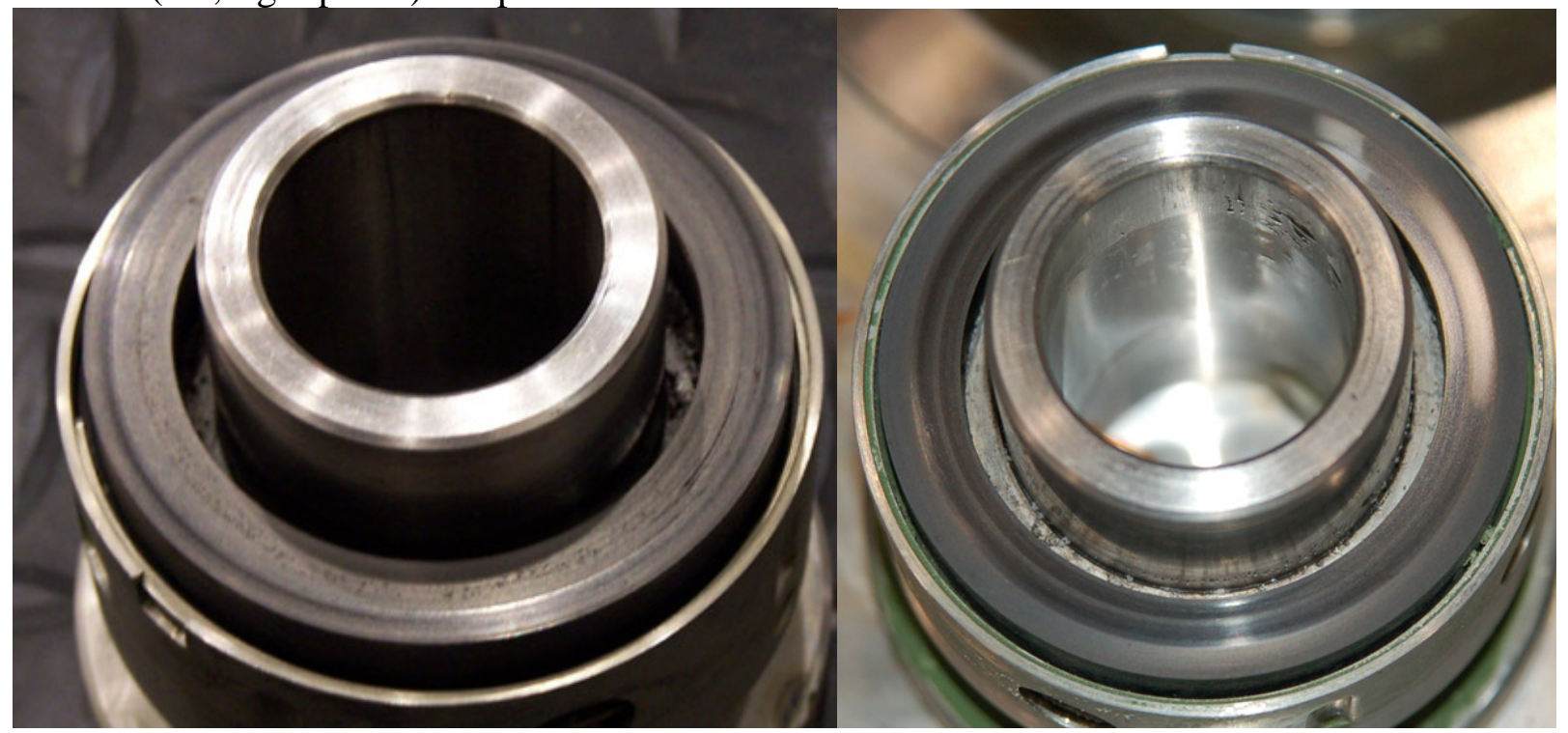

Figure 16 Rotor Portion of Air Seal after 20 3/4 Hours (left photo) and 143 1/2 hours (right photo) of Operation 
Figure 17 shows the stationary part of the seal after the first 20 hours and 44 minutes of operation and then after 143 hours and 28 minutes of operation.

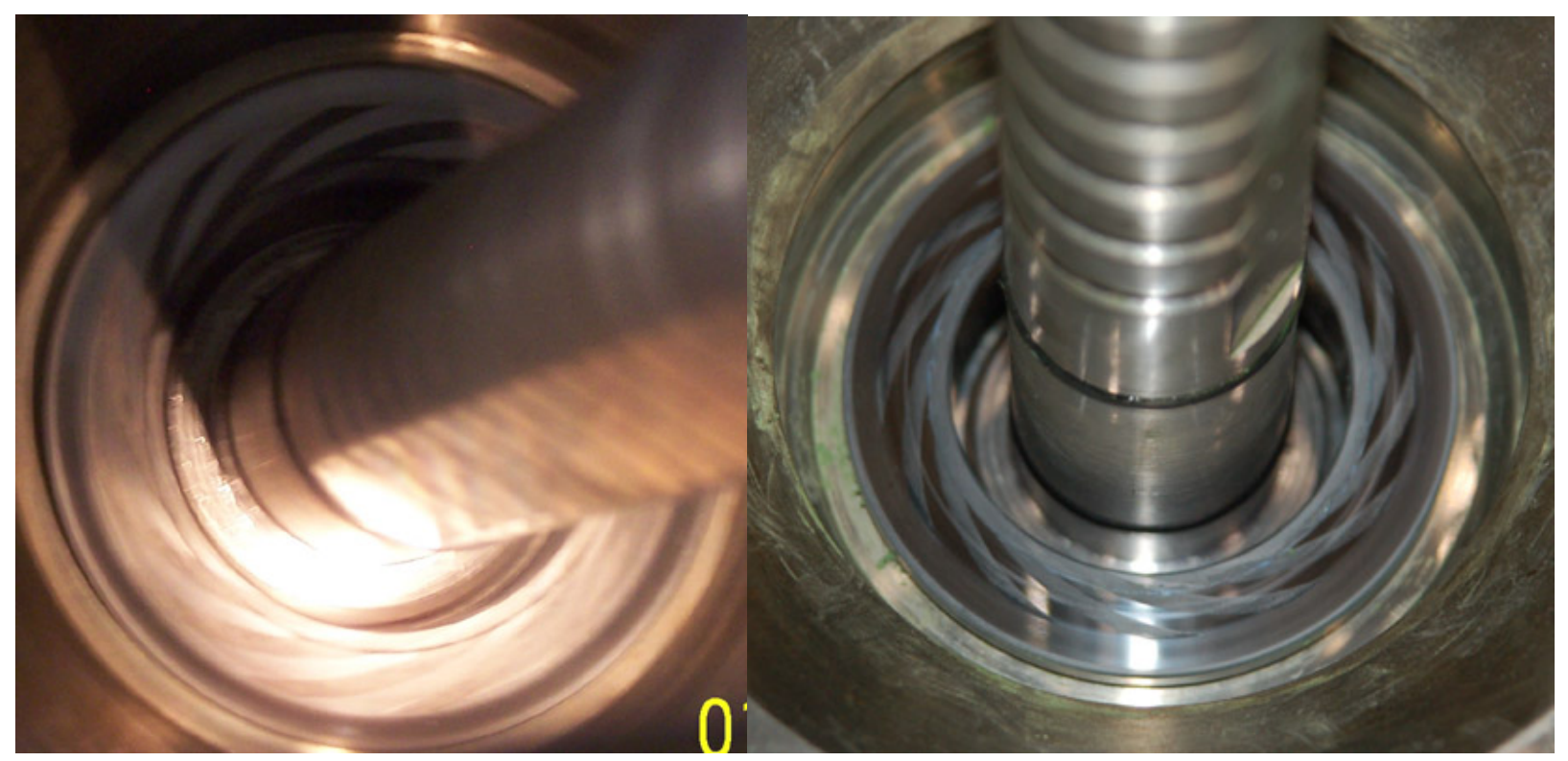

Figure 17 Stationary Portion of Air Seal after 20 3/4 hours (left photo) and 143 1/2 hours (right photo) of Operation

The carbon face of the rotor is showing polishing in the area indicative of initial wear. This polishing is due to contact of the seal faces, primarily at startup and shutdown, when there is not enough velocity to cause liftoff for the faces. No evidence of the passing of process fluid was observed. Very little change to the air channeling grooves on the stationary was observed, though no depth measurements were obtained since these measurements would have required the removal of the seal stationary. 
Figure 18 and Figure 19 show the condition of the bushing set at the bottom of the filter after 143 hours and 28 minutes of operation. Some polishing can be observed on the bottom of the shaft bushing as well as the receiver bushing. The shaft bushing is not supported and is held in place by a sealant. This sealant was compromised by the process fluid allowing the shaft bushing to contact the bottom of the receiver bushing. It is recommended that the shaft bushing be updated to allow it to be held in place by a retaining ring as well as incorporated grooves to allow for additional cooling flow.

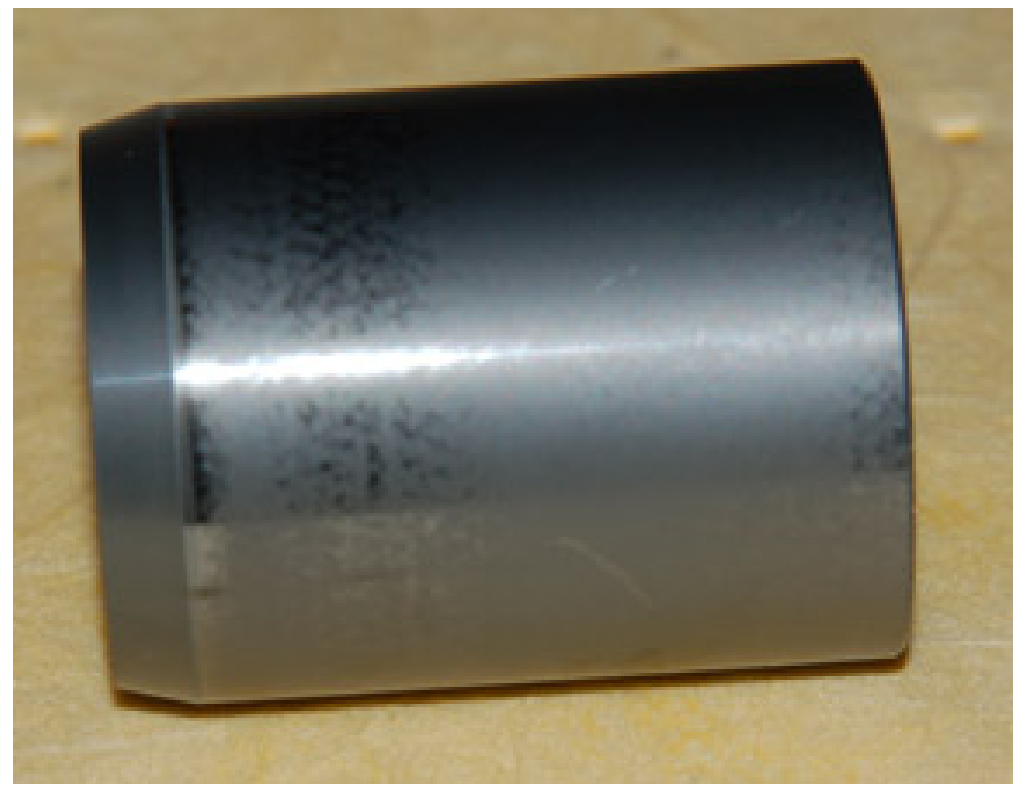

Figure 18. Shaft Bushing after $143 \frac{1}{1} 2$ hours of Operation

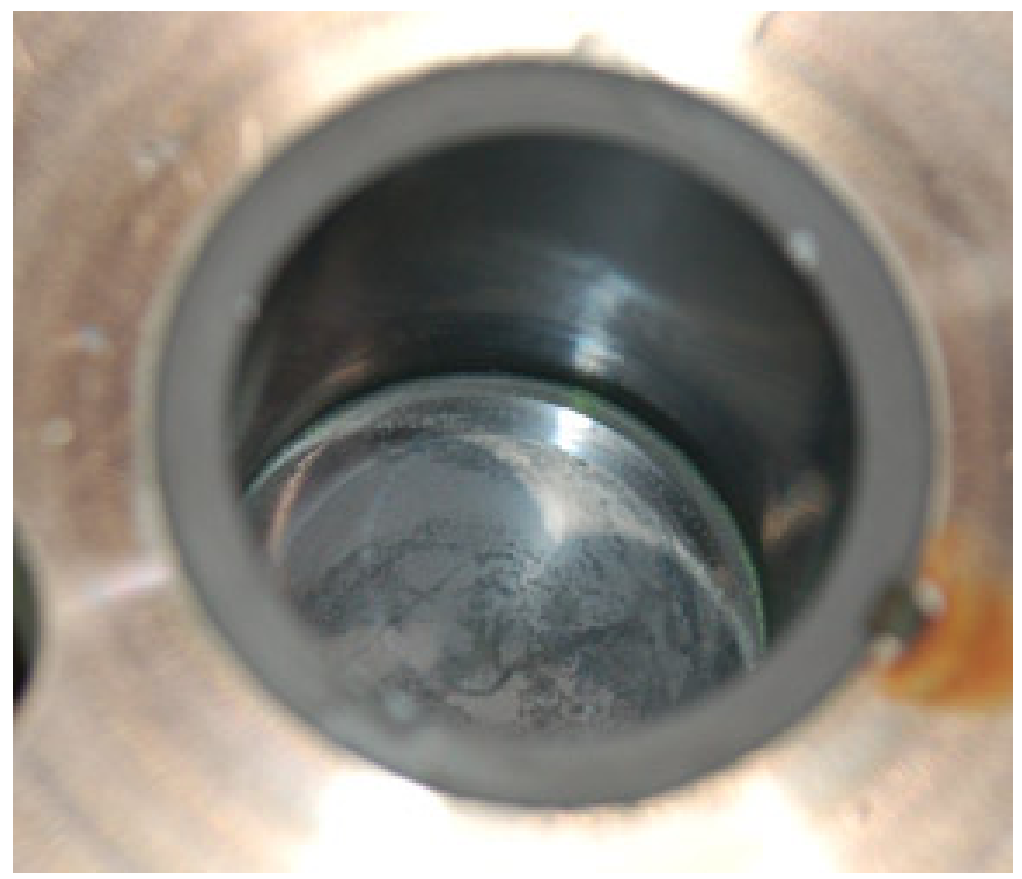

Figure 19. Receiver Bushing after 143 1/2 hours of Operation 
Figure 20 shows the current and power draw by the filter motor during operation.

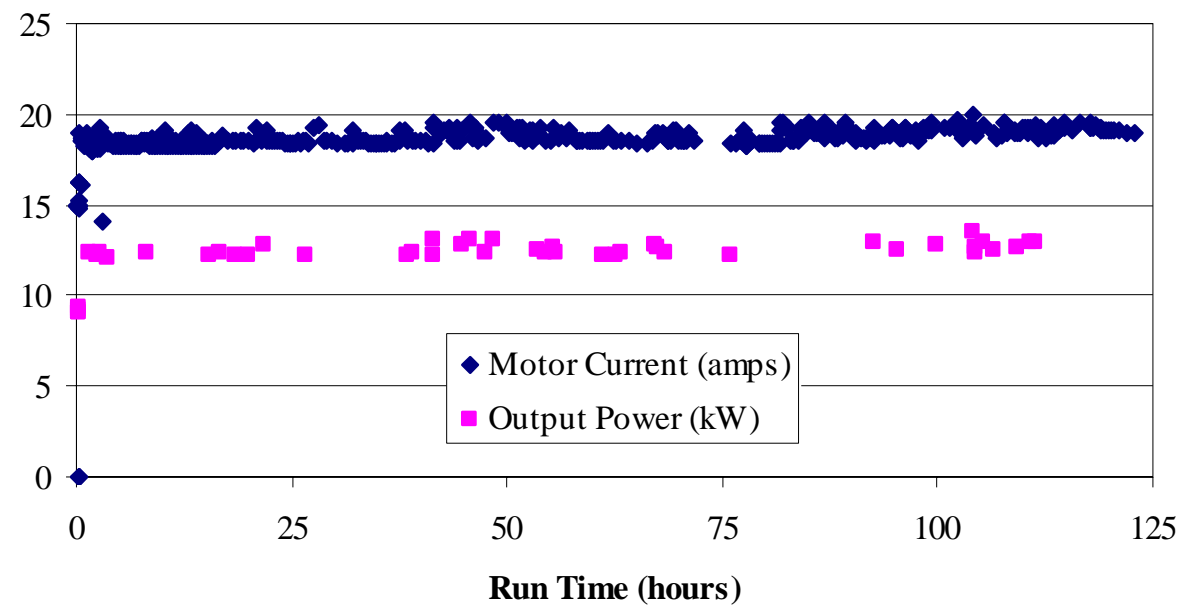

Figure 20. Filter Motor Power and Current Draw

The maximum current rating on the motor is 24.1 amps at 460 volts. No dramatic power or current increases were required as the insoluble solids loadings were increased in the process fluid. 
WSRC-STI-2008-00339

Revision 0

\section{CONCLUSIONS}

The conclusions from this testing follow.

- The filter flux at $0.06 \mathrm{wt} \%$ solids reached a near constant value at an average of $0.26 \mathrm{gpm} / \mathrm{ft}^{2}$ (6.25 gpm total).

- The filter flux at 0.29 wt \% solids reached a near constant value at an average of $0.17 \mathrm{gpm} / \mathrm{ft}^{2}$ (4 gpm total).

- The filter flux at $1.29 \mathrm{wt} \%$ solids reached a near constant value at an average of $0.10 \mathrm{gpm} / \mathrm{ft}^{2}$ (2.4 gpm total).

- Because of differences in solids loadings, a direct comparison between crossflow filter flux and rotary filter flux is not possible. The data show the rotary filter produces a higher flux than the crossflow filter, but the improvement is not as large as seen in previous testing.

- Filtrate turbidity measured $<4$ NTU in all samples collected.

- During production, the filter should be rinsed with filtrate or dilute caustic and drained prior to an extended shutdown to prevent the formation of a layer of settled solids on top of the filter disks.

- Inspection of the seal faces after 140 hours of operation showed an expected amount of initial wear, no passing of process fluid through the seal faces, and very little change in the air channeling grooves on the stationary face.

- Some polishing was observed at the bottom of the shaft bushing. The authors recommend improving the shaft bushing by holding it in place with a locking ring and incorporated grooves to provide additional cooling.

- The authors recommend that CH2MHill Hanford test other pore size media to determine the optimum pore size for Hanford waste. 
WSRC-STI-2008-00339

Revision 0

\section{REFERENCES}

1. M. R. Poirier, "Evaluation of Solid-Liquid Separation Technologies to Remove Sludge and Monosodium Titanate from SRS High Level Waste”, WSRC-TR-2000-00288, Rev. 0, August 16, 2000.

2. M. R. Poirier, "Filtration Systems, Inc., Report for SRS SpinTek Rotary Microfilter Testing”, WSRC-TR-2001-00214, Rev. 0, May 4, 2001.

3. D. T. Herman, M. R. Poirier, and S. D. Fink, "Testing of the SpinTek Rotary Microfilter Using Actual Waste”, WSRC-TR-2003-00030, Rev. 1, December 2003.

4. M. R. Poirier, D. T. Herman, S. D. Fink, R. Haggard, T. Deal, C. Stork, and V. Van Brunt, "Pilot-Scale Testing of a SpinTek Rotary Microfilter with SRS Simulated High Level Waste”, WSRC-TR-2003-00071, February 3, 2003.

5. D. T. Herman, M. R. Poirier, and S. D. Fink, "Testing and Evaluation of the Modified Design of the 25-Disk Rotary Microfilter”, WSRC-STI-2006-00073, Rev. 0, August 2006.

6. M.G. Thien, M.E. Johnson, D.W. Reberger, R.D. Williamson, C.M. Musick, and M.D. Roupe, "Evaluation of Starting the Waste Treatment and Immobilization Plant(WTP) Low Activity Waste LAW) Facility First”, RPP-29981, Rev. 0, July 2006, CH2MHill Hanford Group, Inc., Richland, WA, June 2006.

7. K. Gerdes, "Rotary Microfilter for Hanford Tank Waste”, TTP SR-07-1101, March 18, 2008.

8. M. R. Poirier, D. T. Herman, D. B. Stefanko, S. D. Fink, “Task Technical and Quality Assurance Plan for the Testing of the Rotary Microfilter to Support Hanford Applications”, WSRC-RP-2007-00794, Rev 0, September 6, 2007.

9. R. E. Eibling and C. A. Nash, "Hanford Waste Simulants Created to Support the Research and Development on the River Protection Project - Waste Treatment Plant", WSRC-TR-2000-00338, February 2001.

10. M. R. Duignan, "Final Report: Pilot-scale Cross-flow Ultrafiltration Test Using a Hanford Site Tank 241-AN-105 Waste Simulant - Envelope A + Entrained Solids", BNF-003-98-0221, Rev. 0, February 23, 2000.

11. R. A. Peterson, C. A. Nash, and D. J. McCabe, "Correlation of Filtrate Flow Rate for Irradiated and Unirradiated Tetraphenylborate Slurries”, WSRC-MS-95-0448. 
WSRC-STI-2008-00339

Revision 0

Appendix A: Test Data

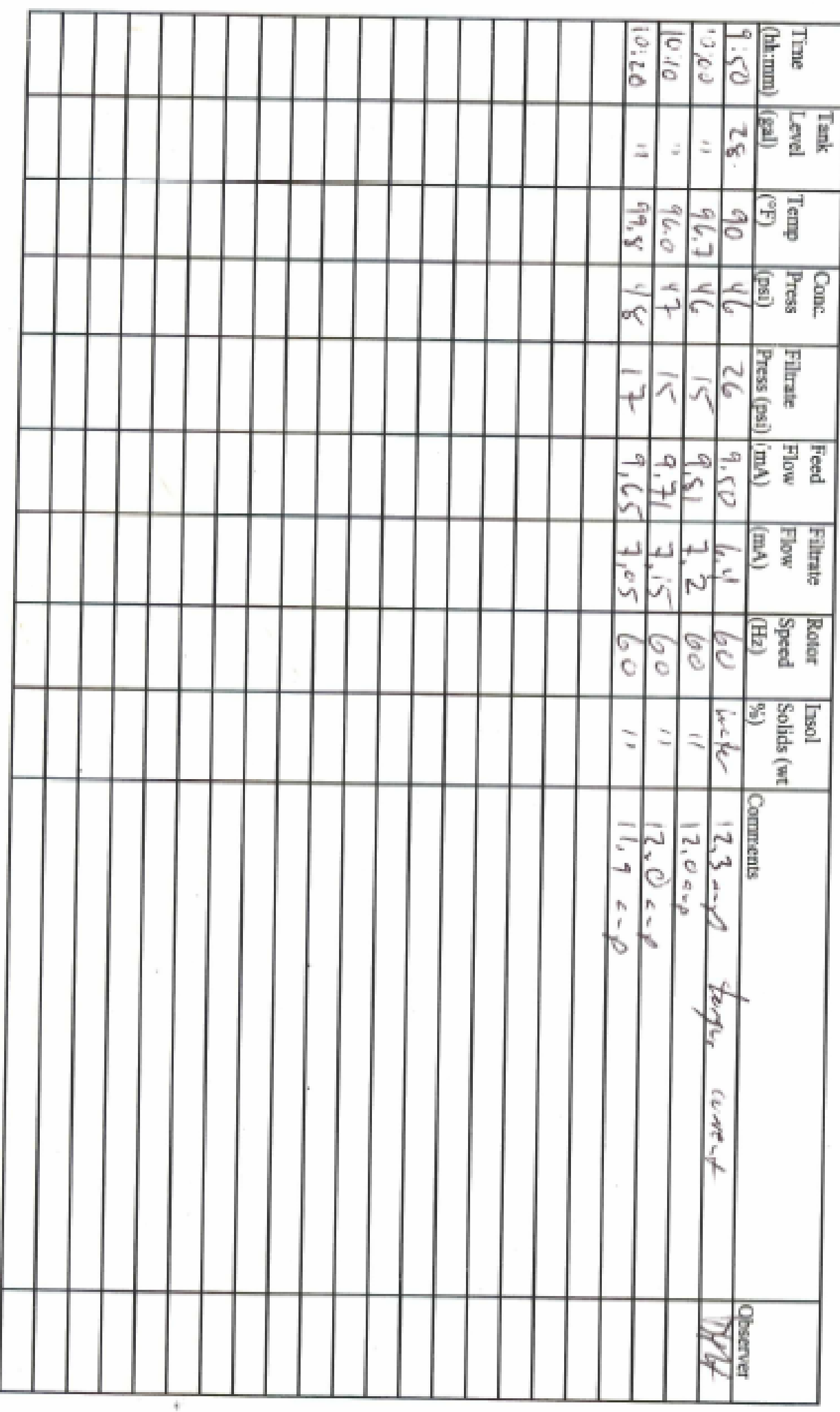


WSRC-STI-2008-00339

Revision 0

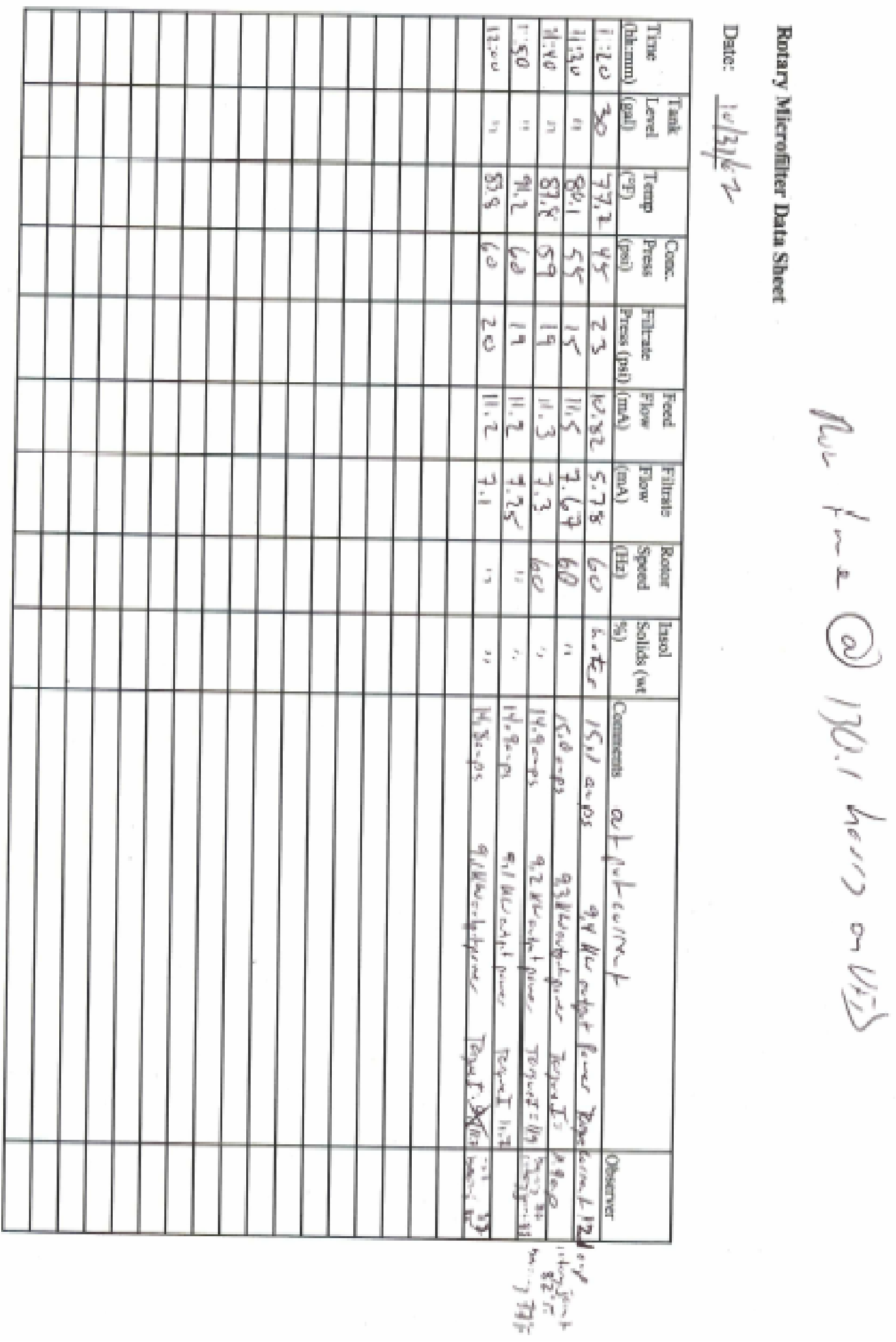


WSRC-STI-2008-00339

Revision 0

$\stackrel{n}{=}$

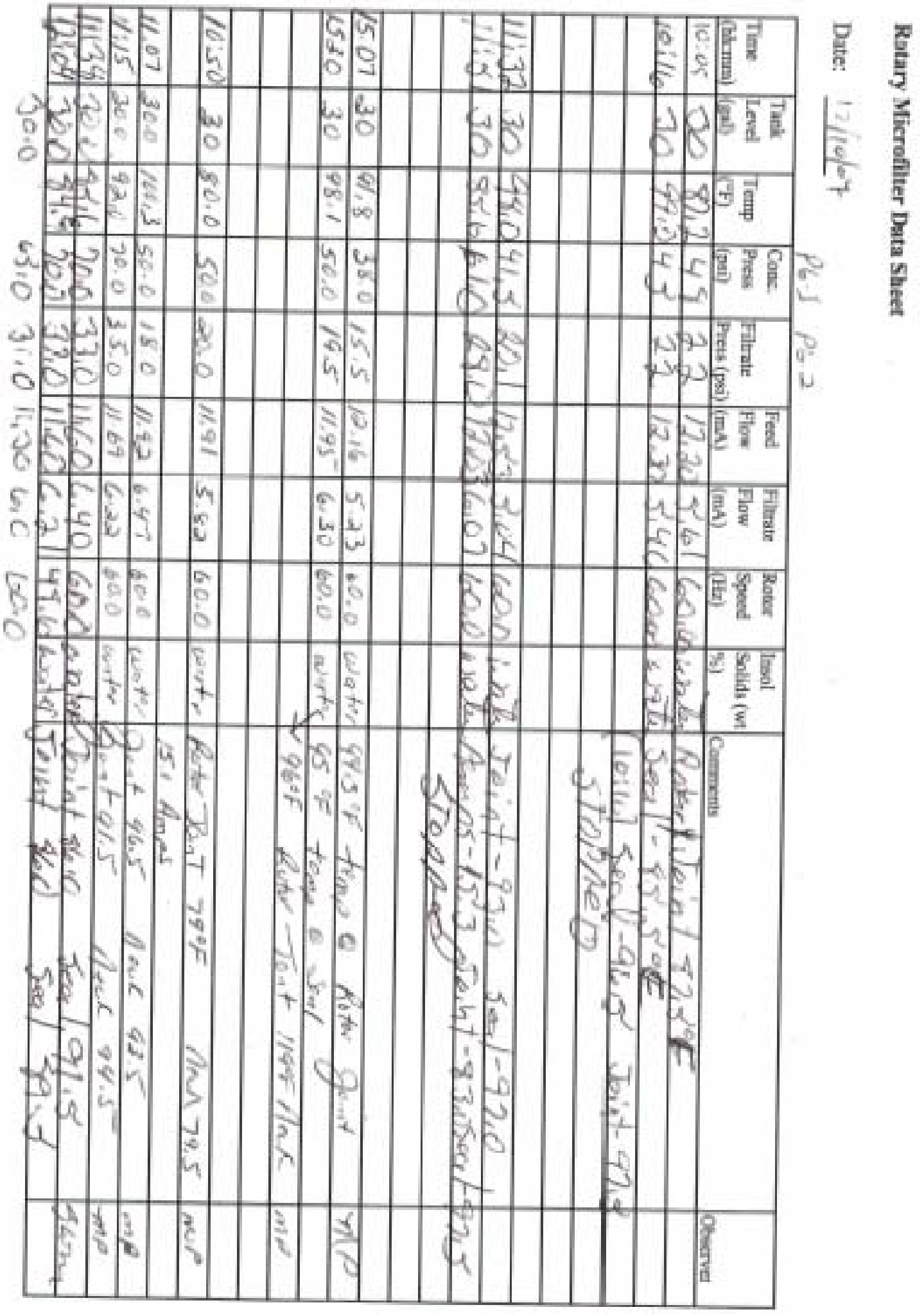


WSRC-STI-2008-00339

Revision 0

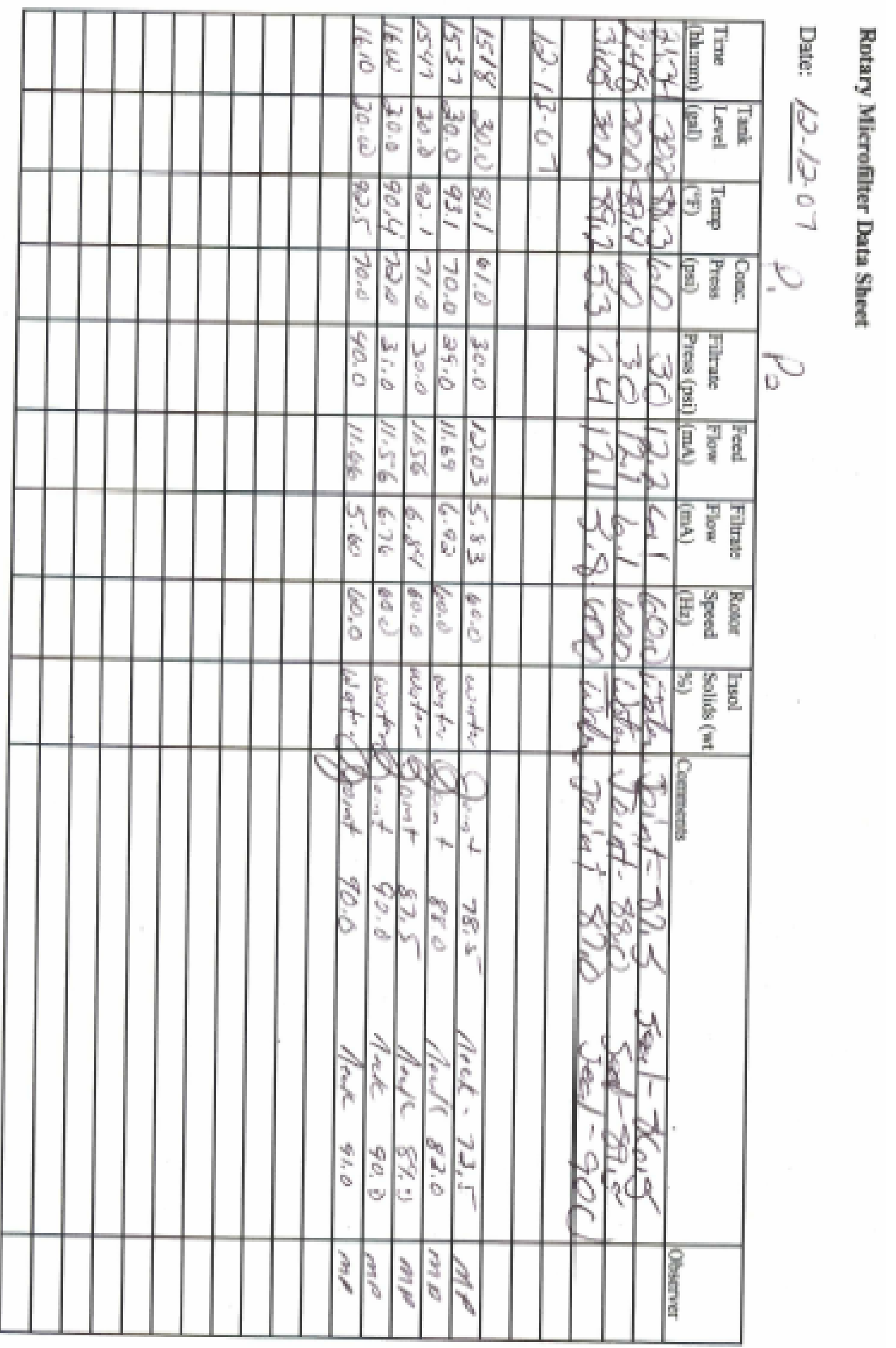


WSRC-STI-2008-00339

Revision 0

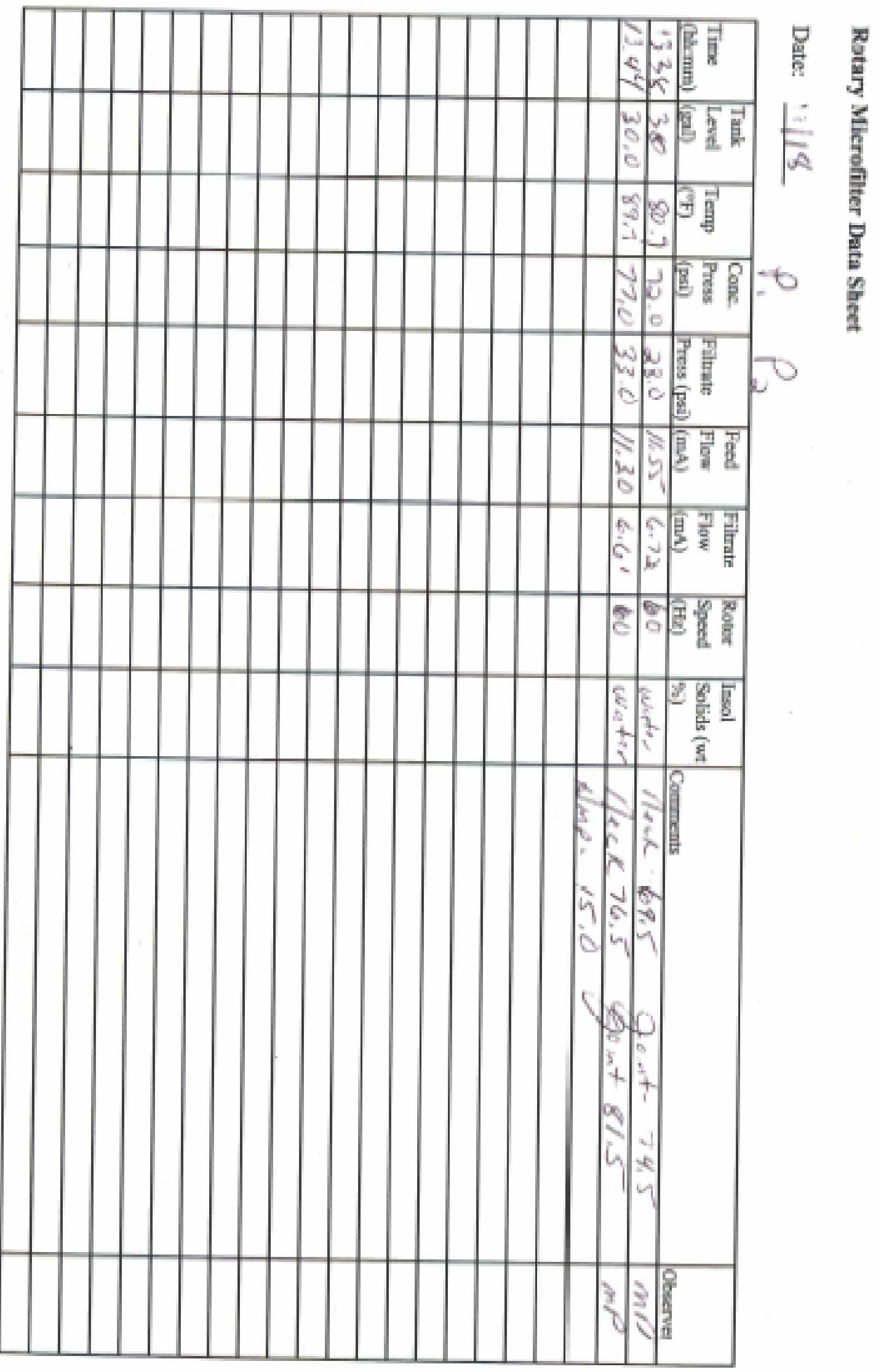


WSRC-STI-2008-00339

Revision 0

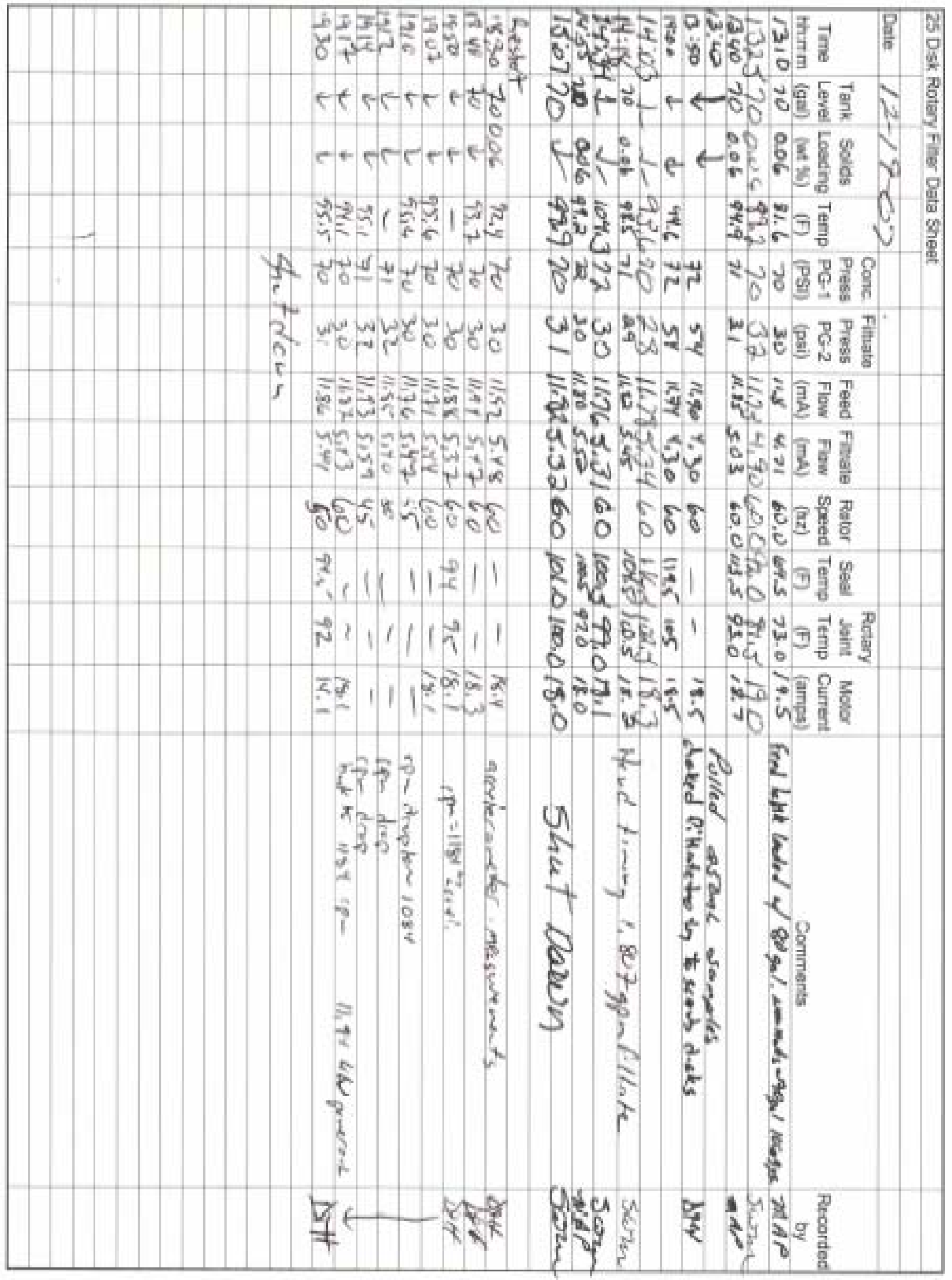


WSRC-STI-2008-00339

Revision 0

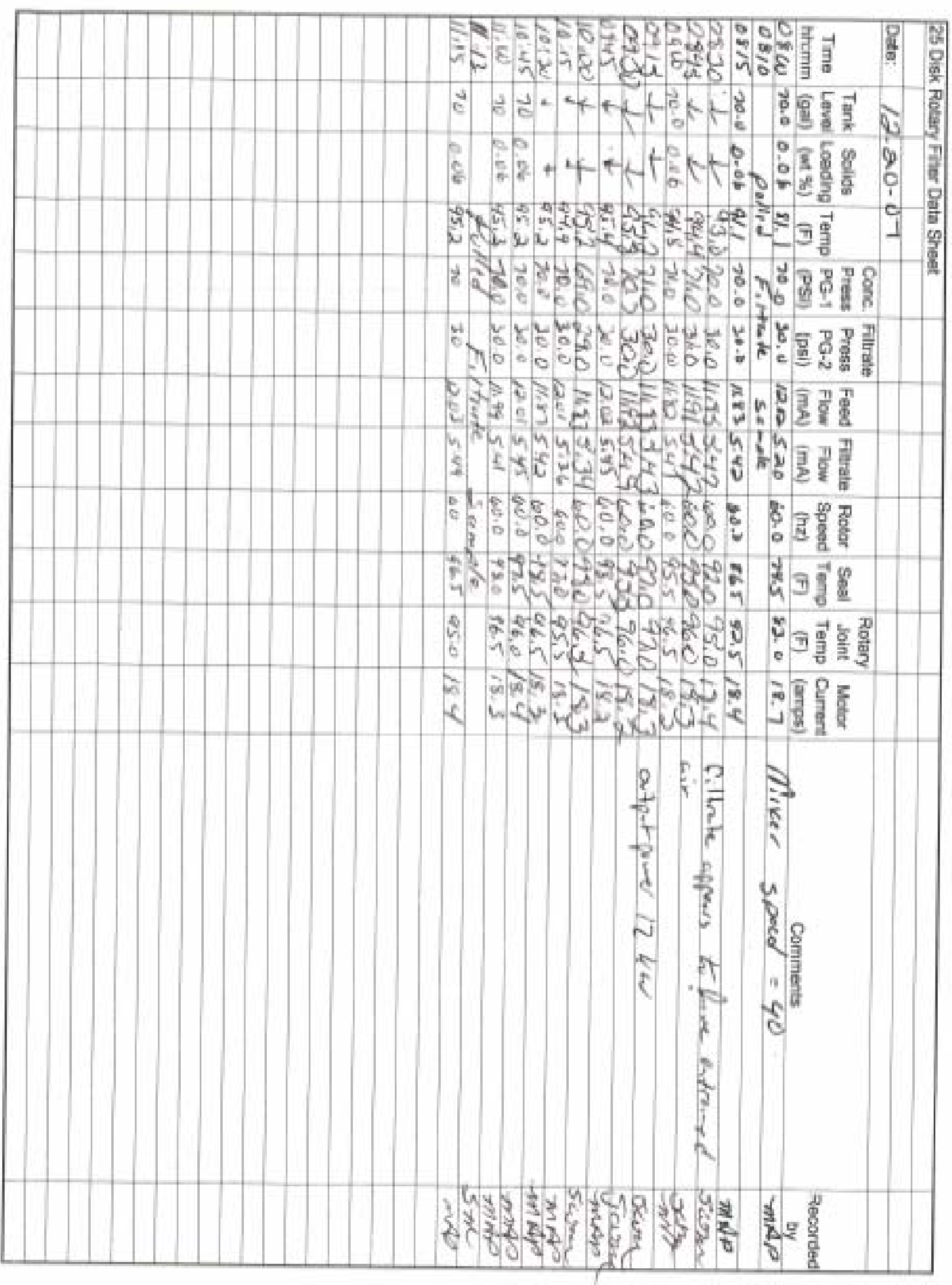


WSRC-STI-2008-00339

Revision 0

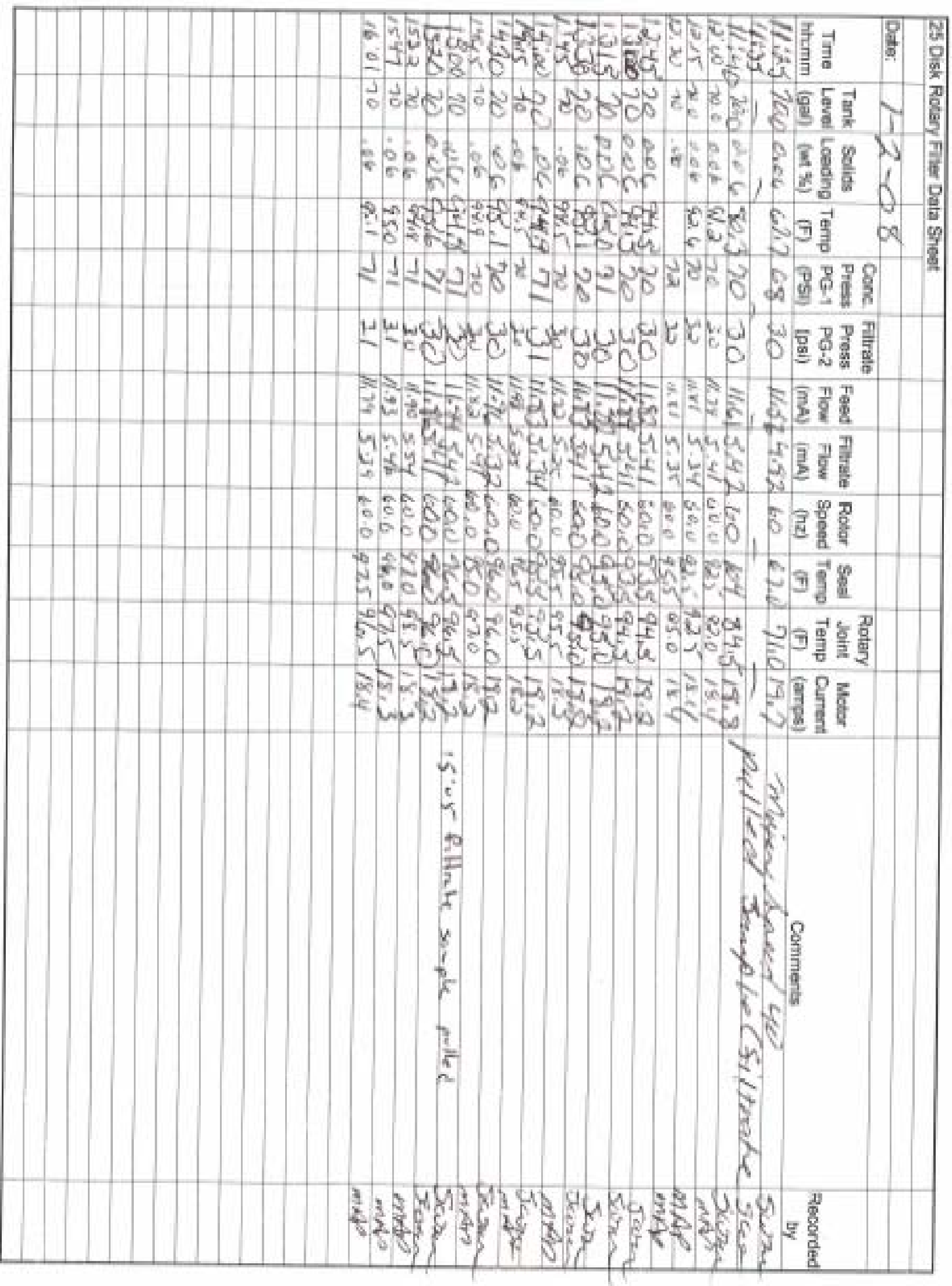


WSRC-STI-2008-00339

Revision 0

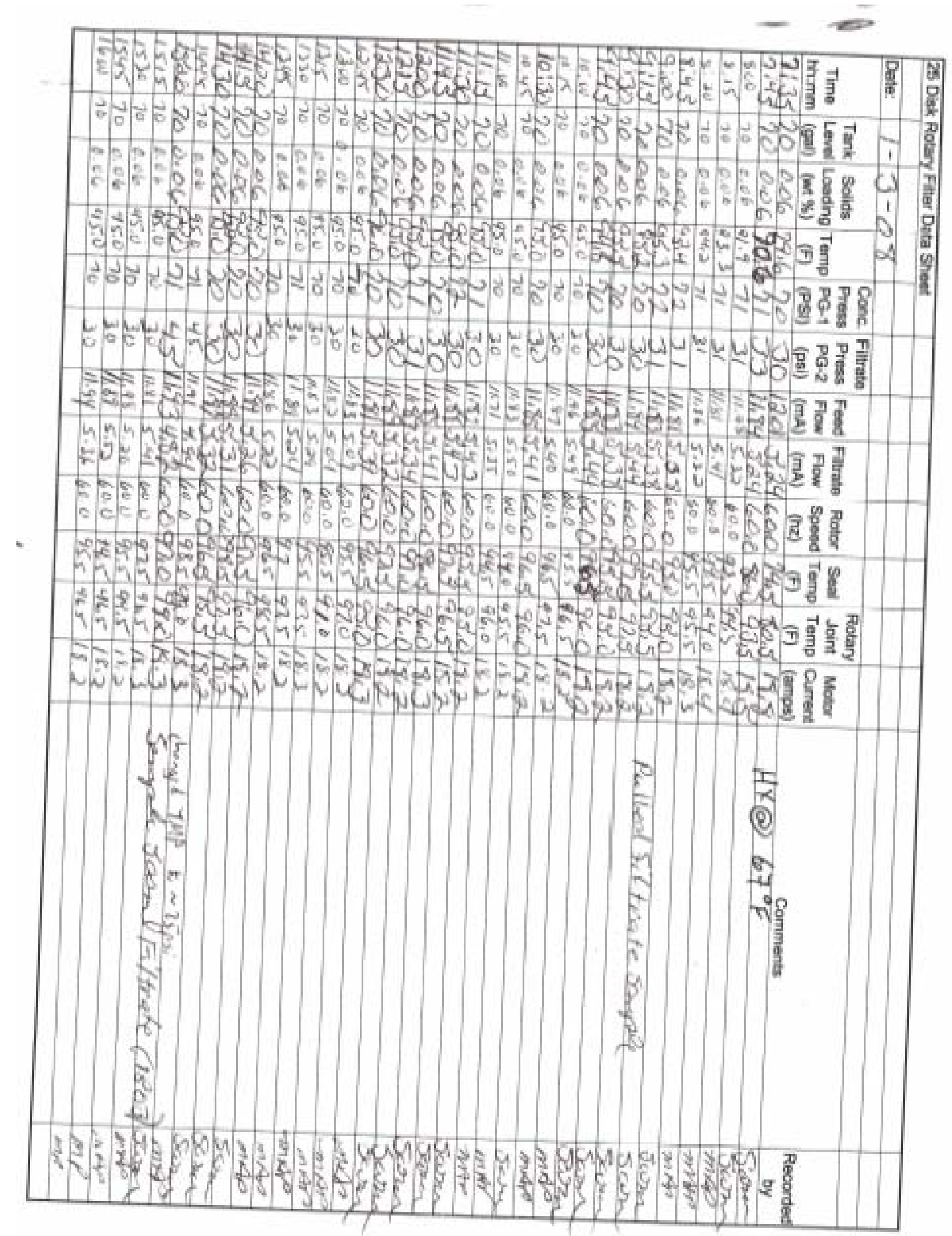


WSRC-STI-2008-00339

Revision 0

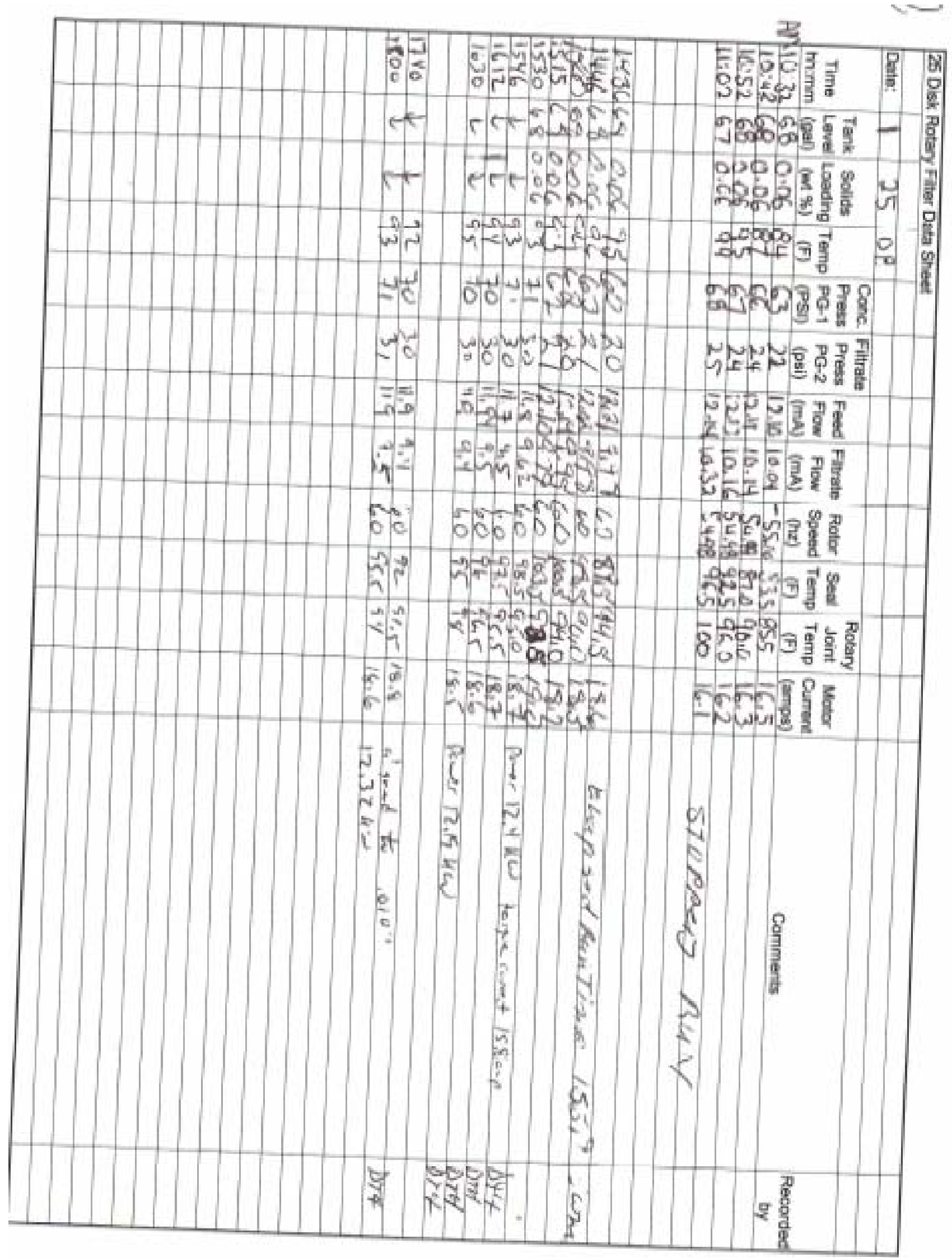


WSRC-STI-2008-00339

Revision 0

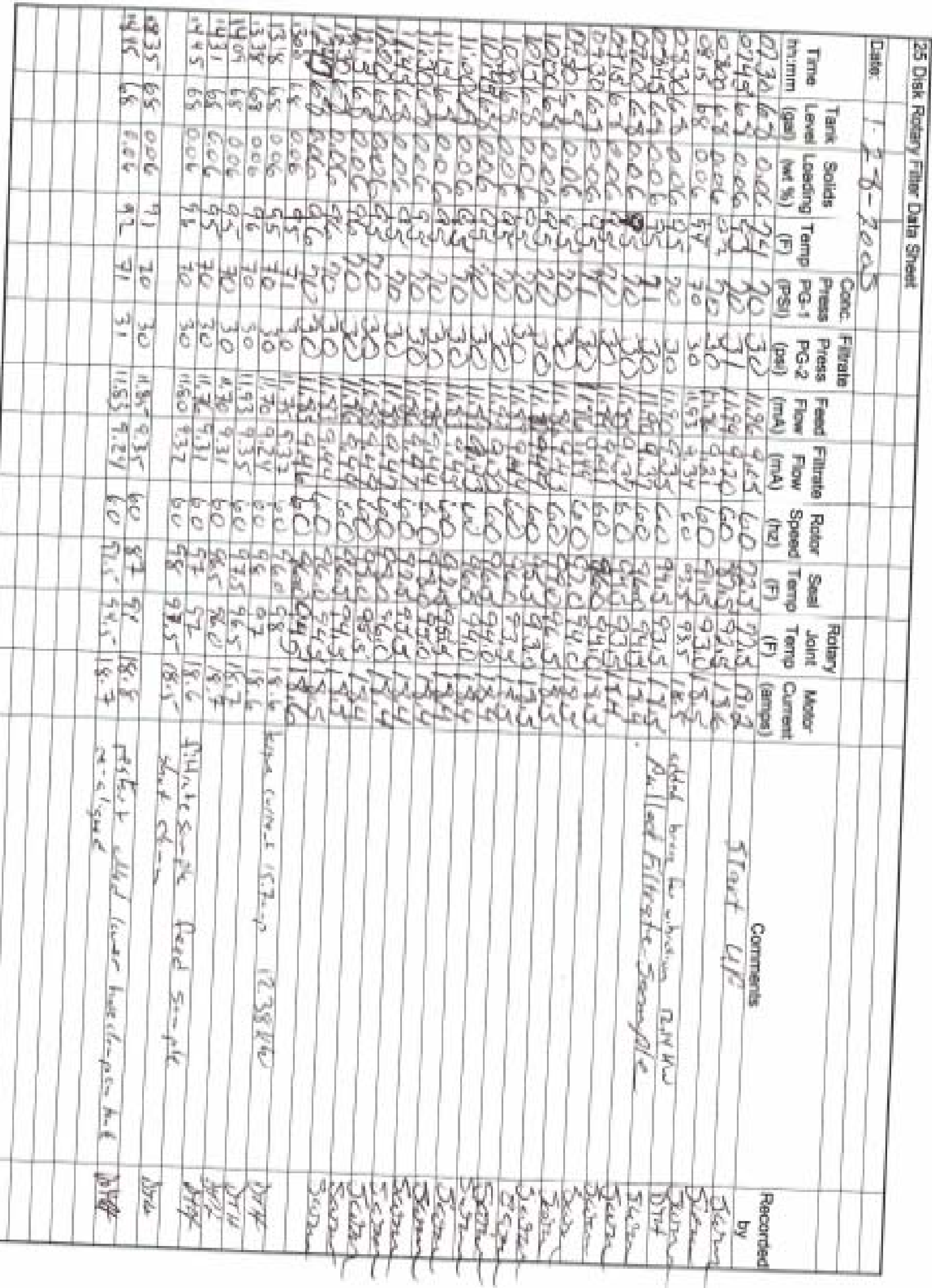


WSRC-STI-2008-00339

Revision 0

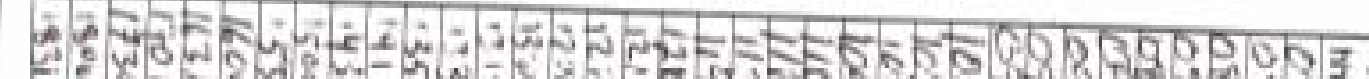

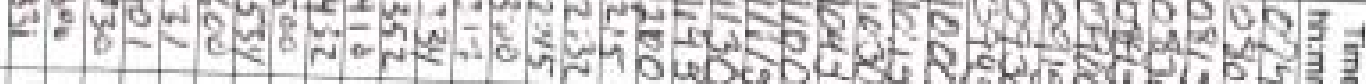

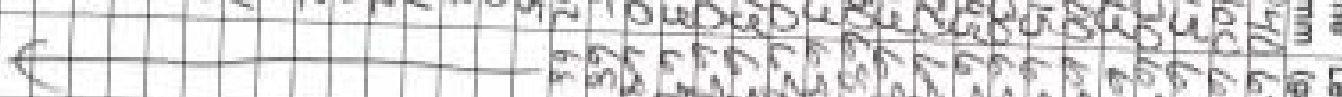

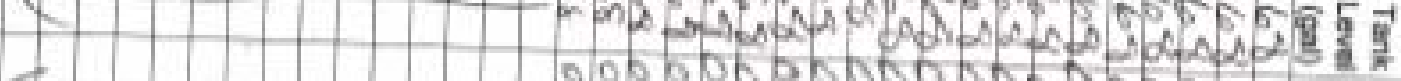

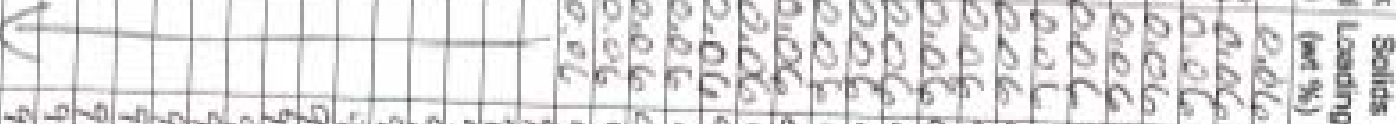

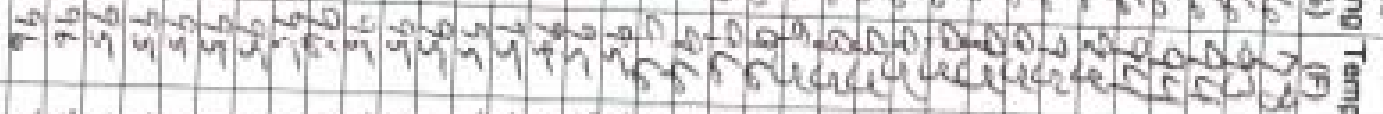

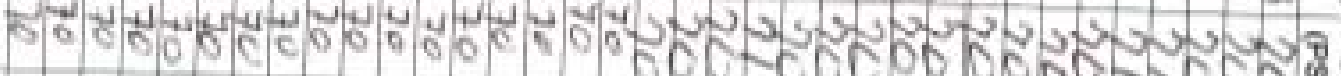

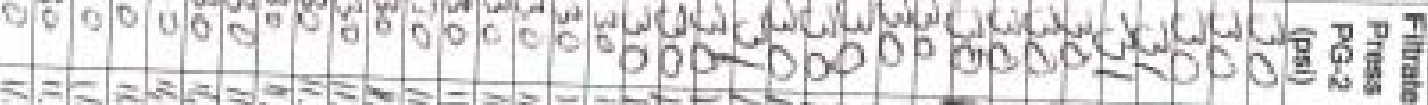

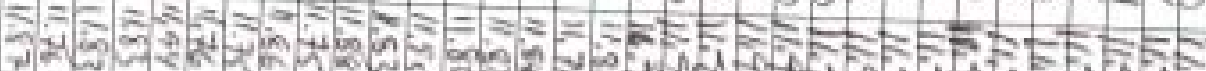

1.

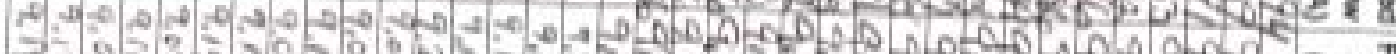

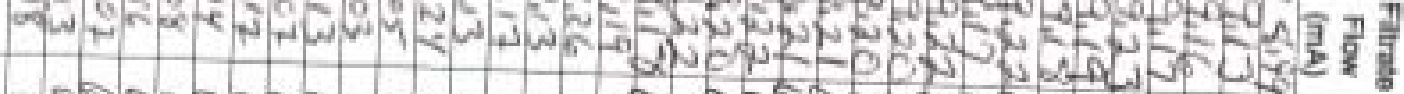

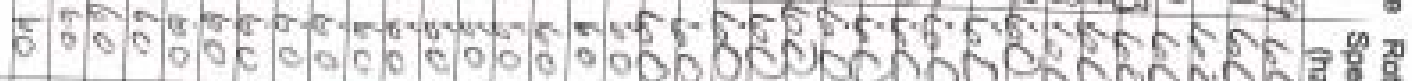

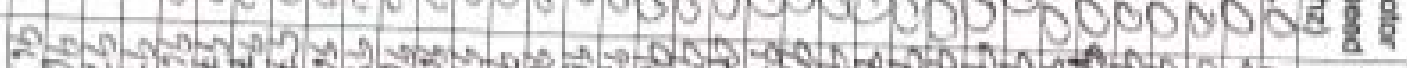

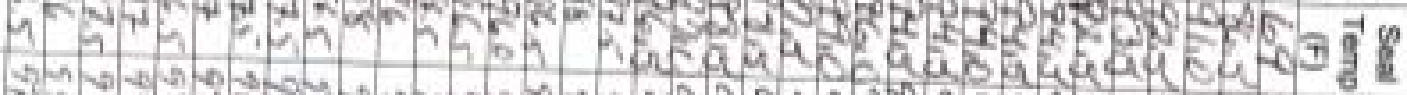

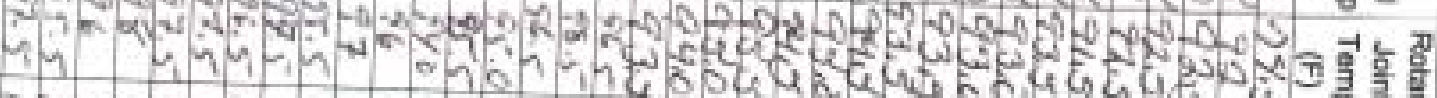

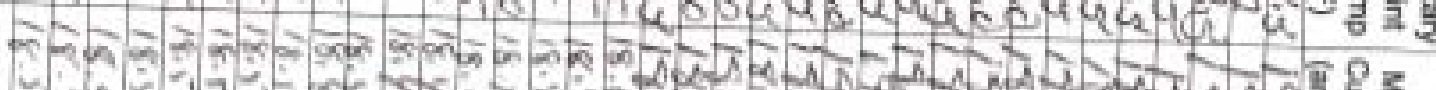

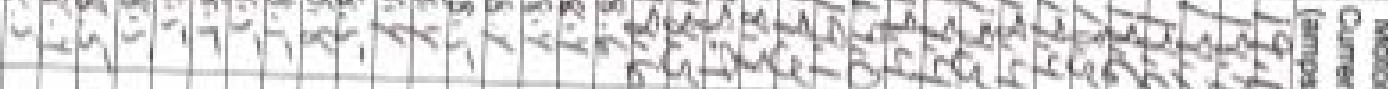

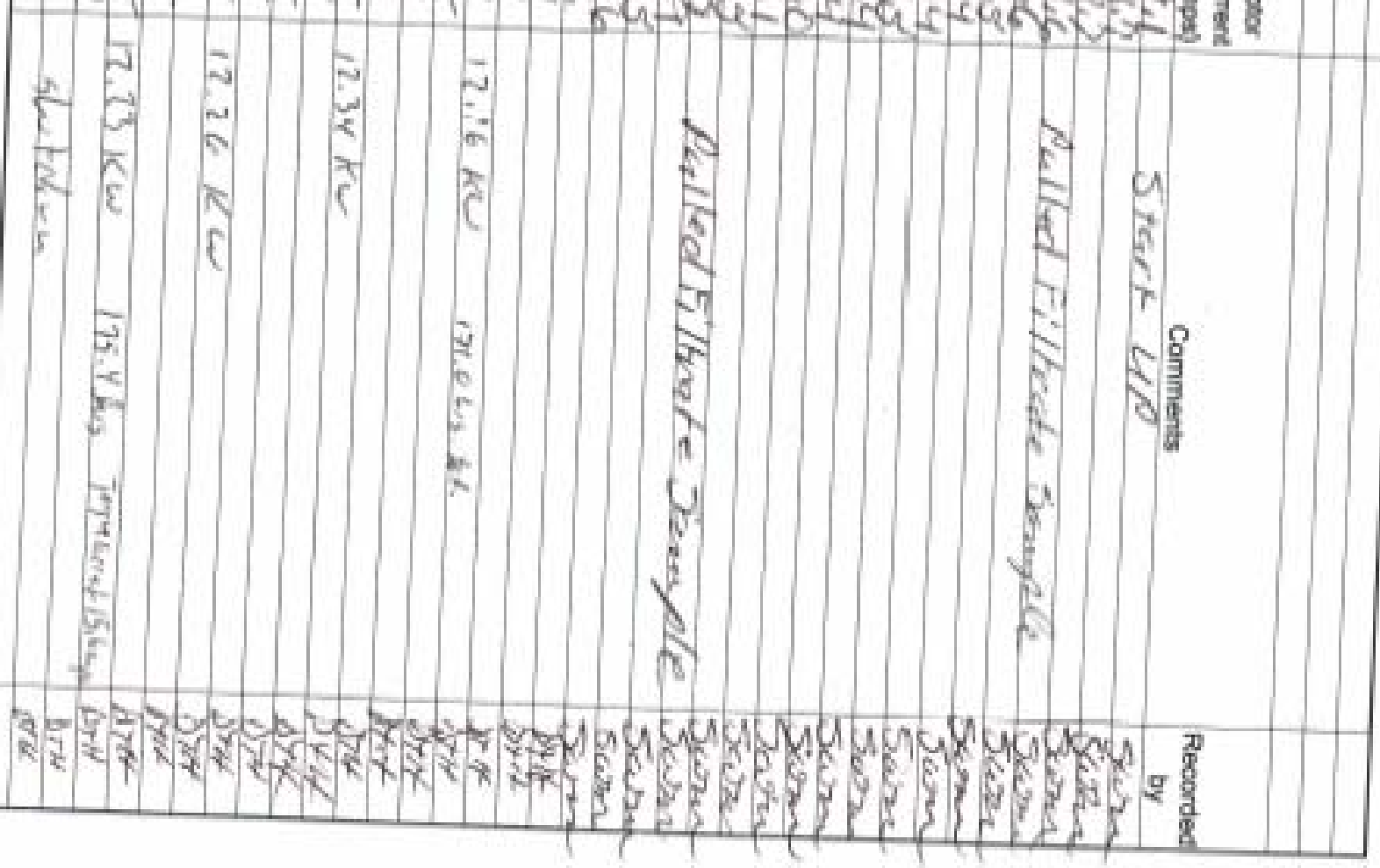


WSRC-STI-2008-00339

Revision 0

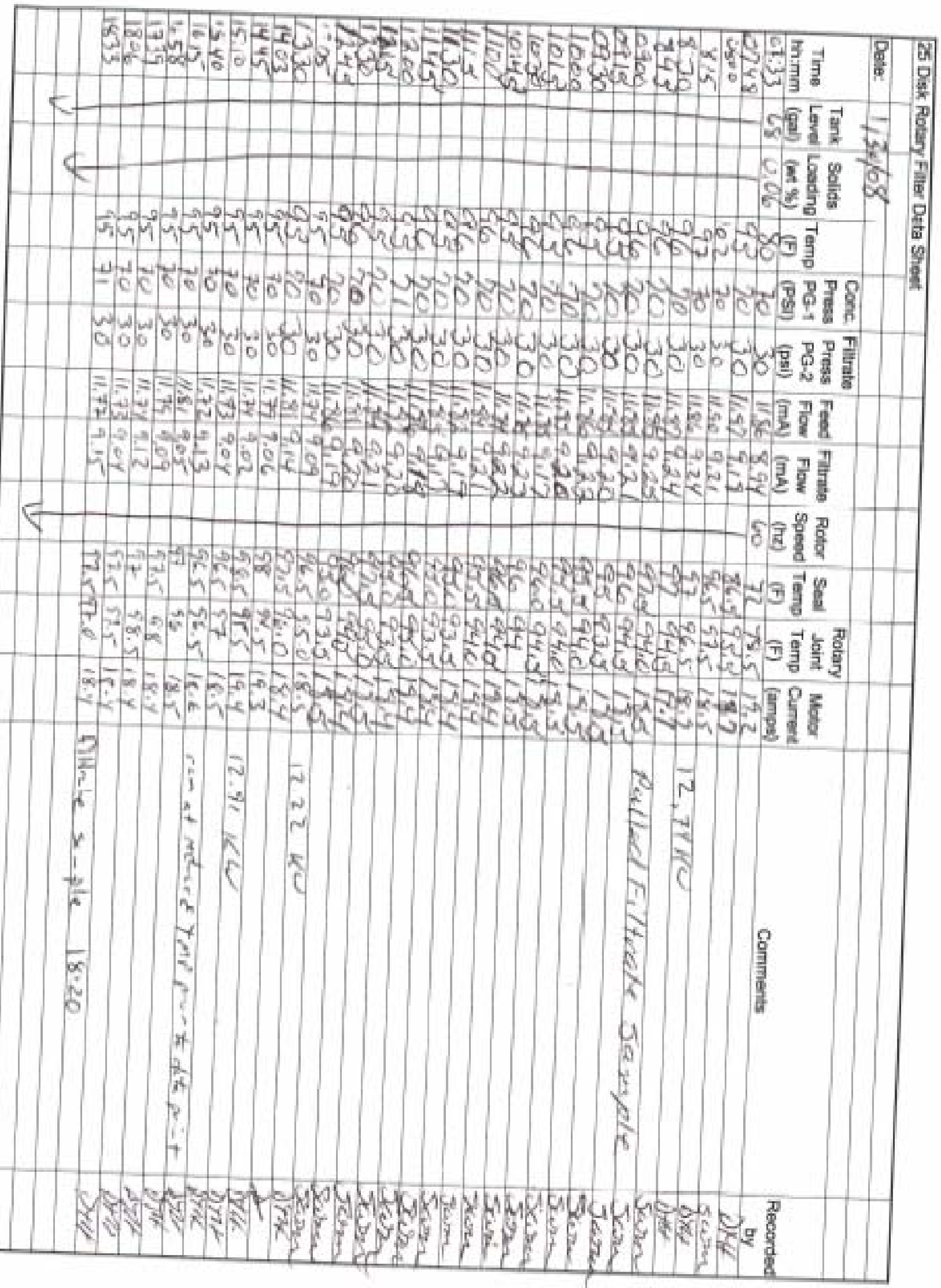


WSRC-STI-2008-00339

Revision 0

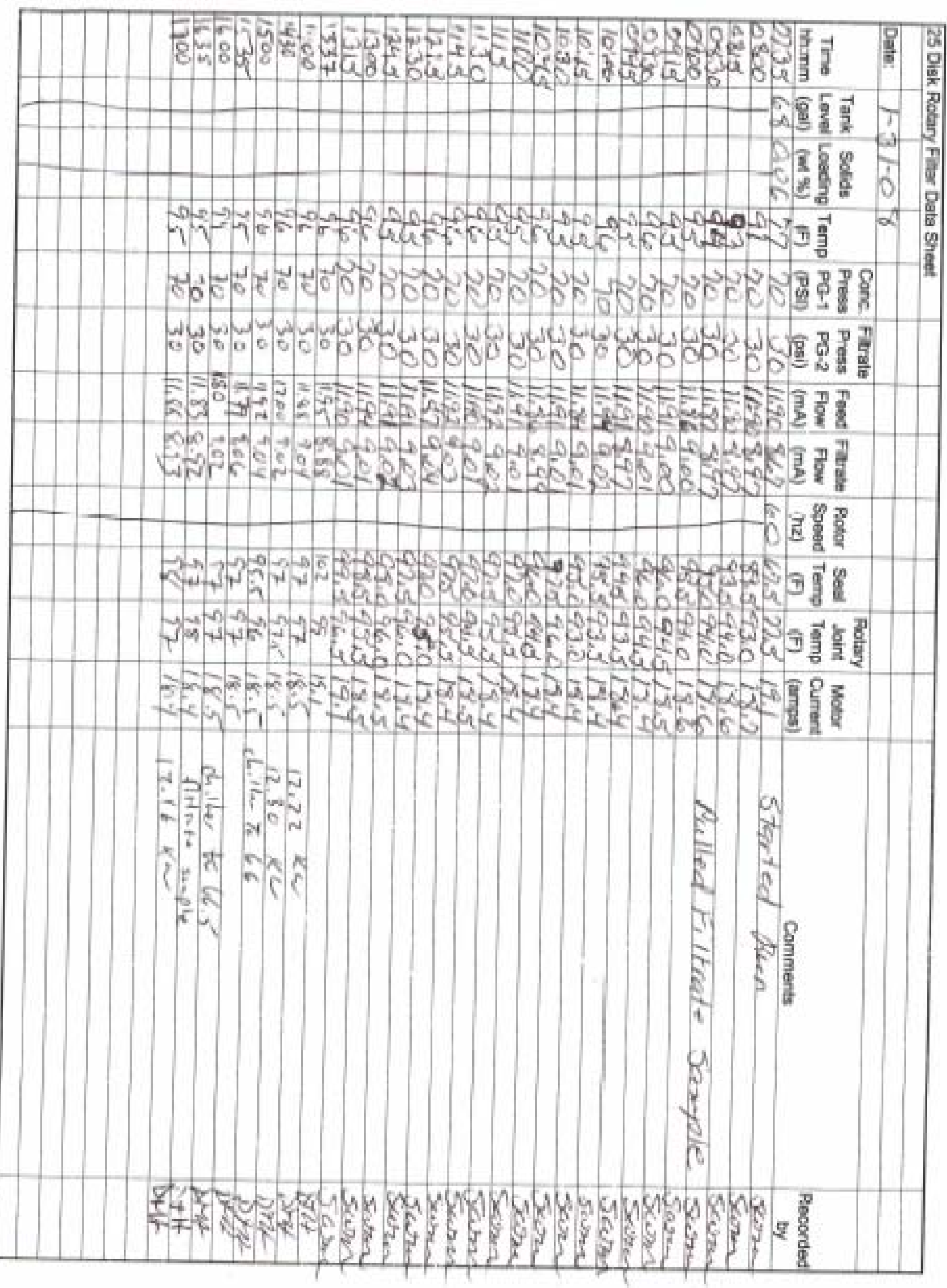


WSRC-STI-2008-00339

Revision 0

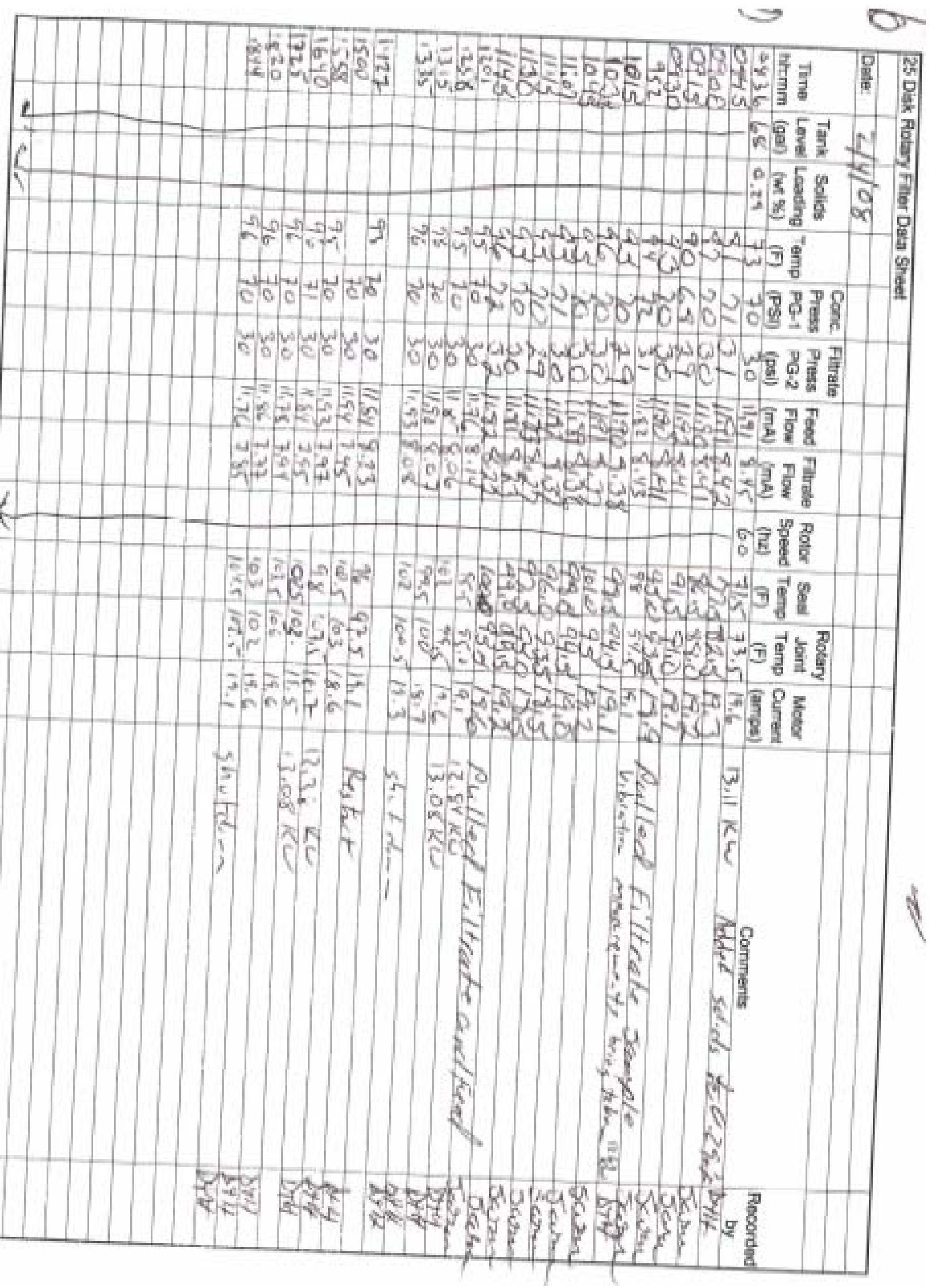


WSRC-STI-2008-00339

Revision 0

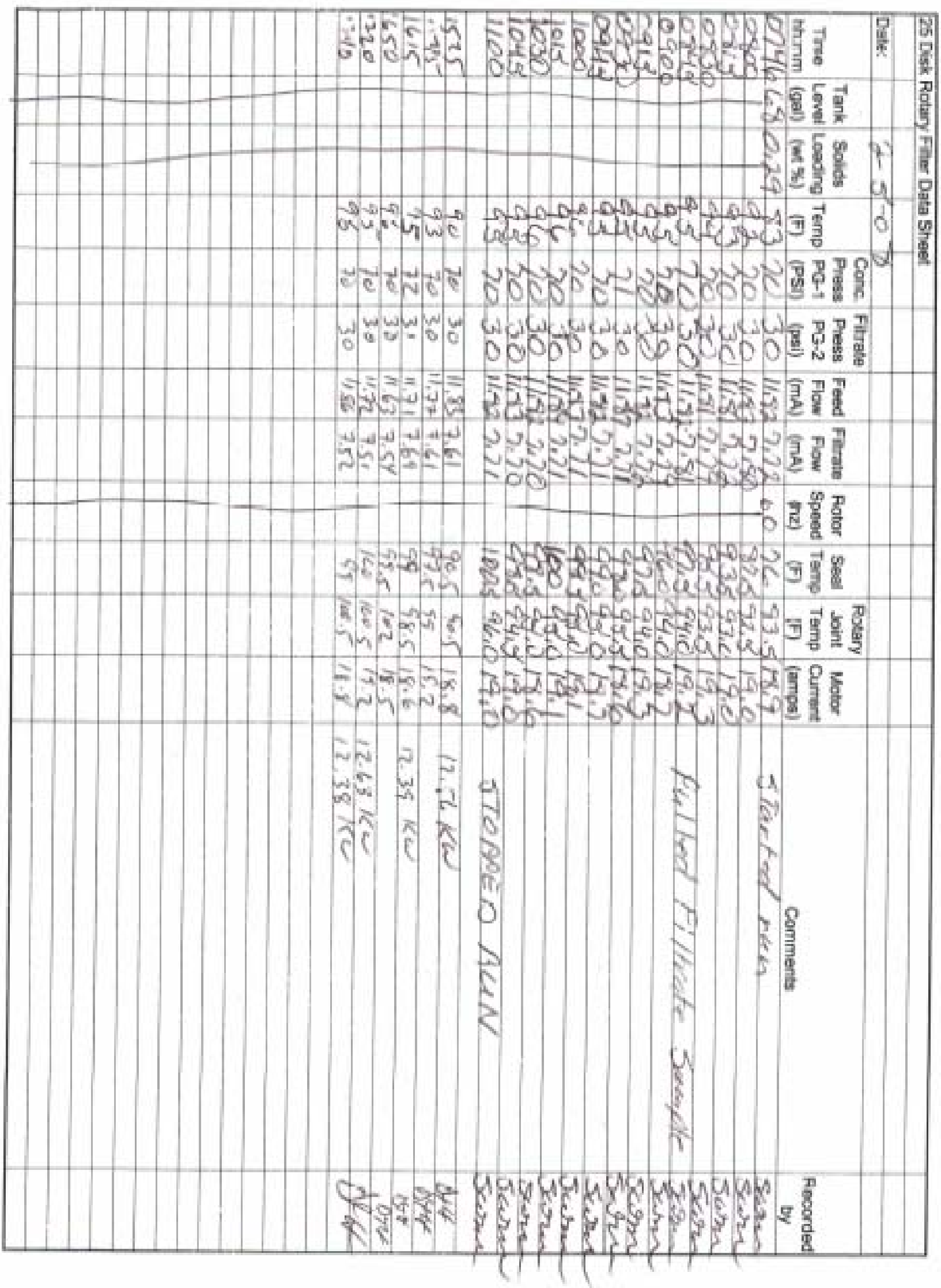


WSRC-STI-2008-00339

Revision 0

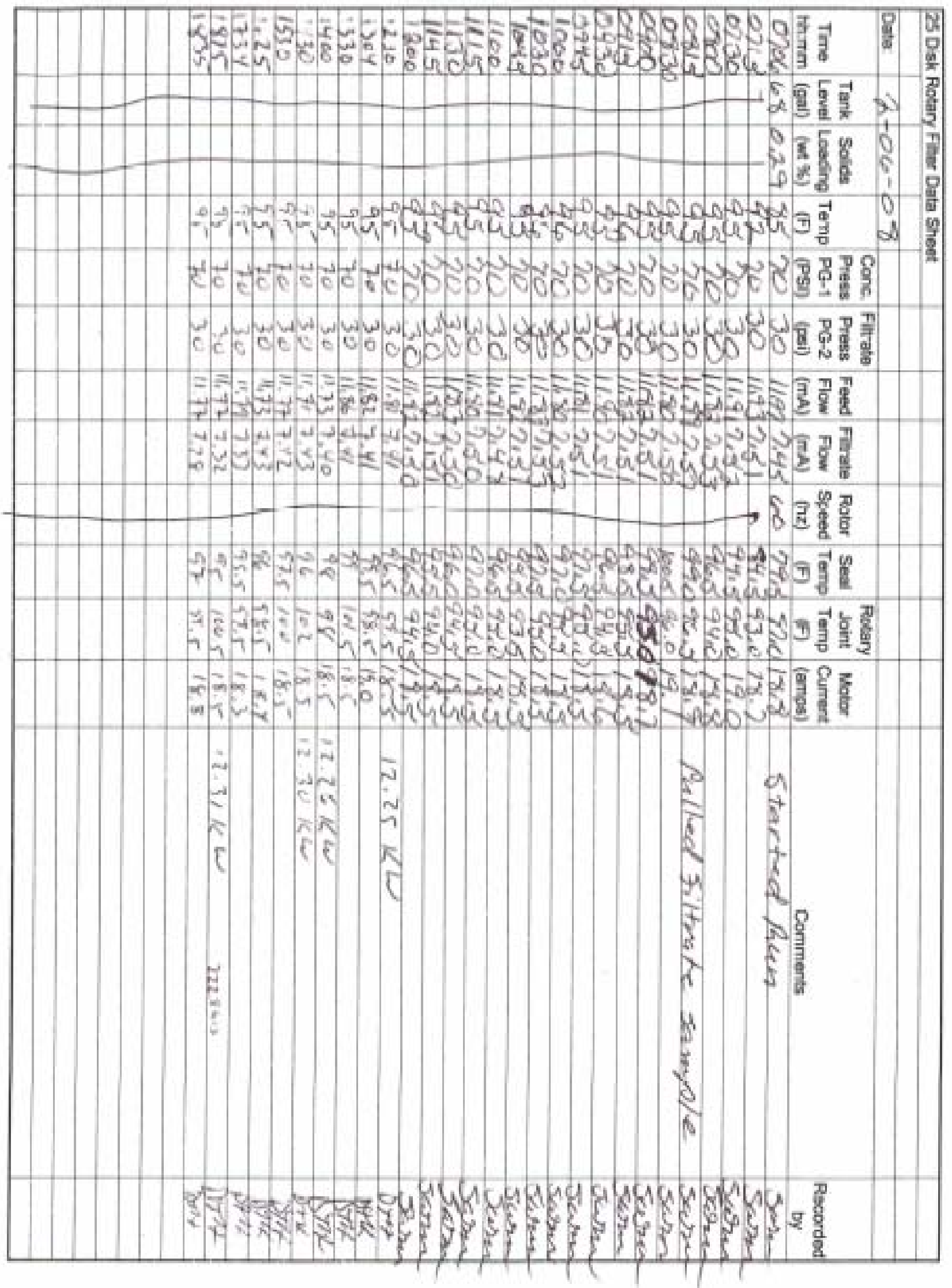


WSRC-STI-2008-00339

Revision 0

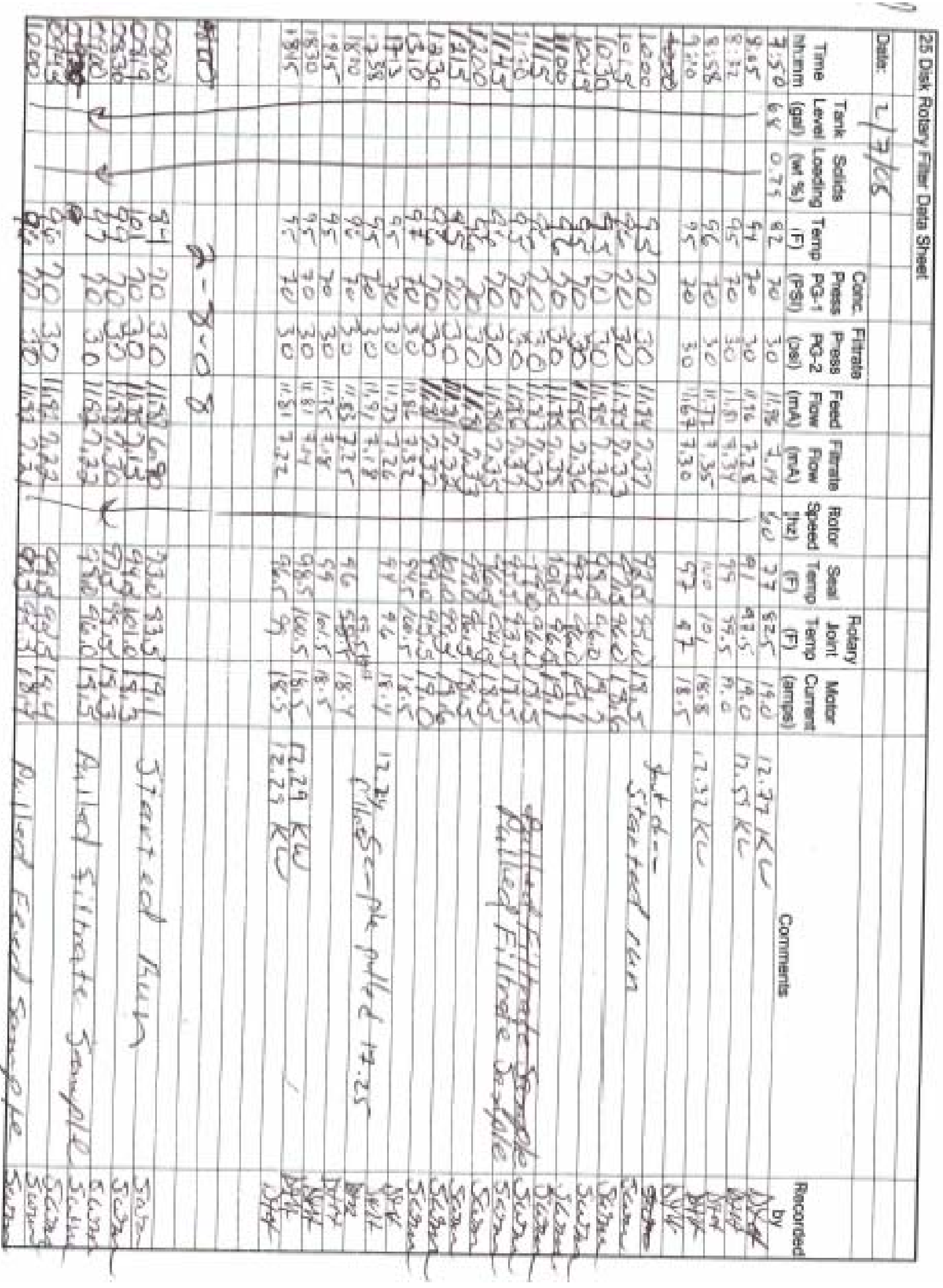


WSRC-STI-2008-00339

Revision 0

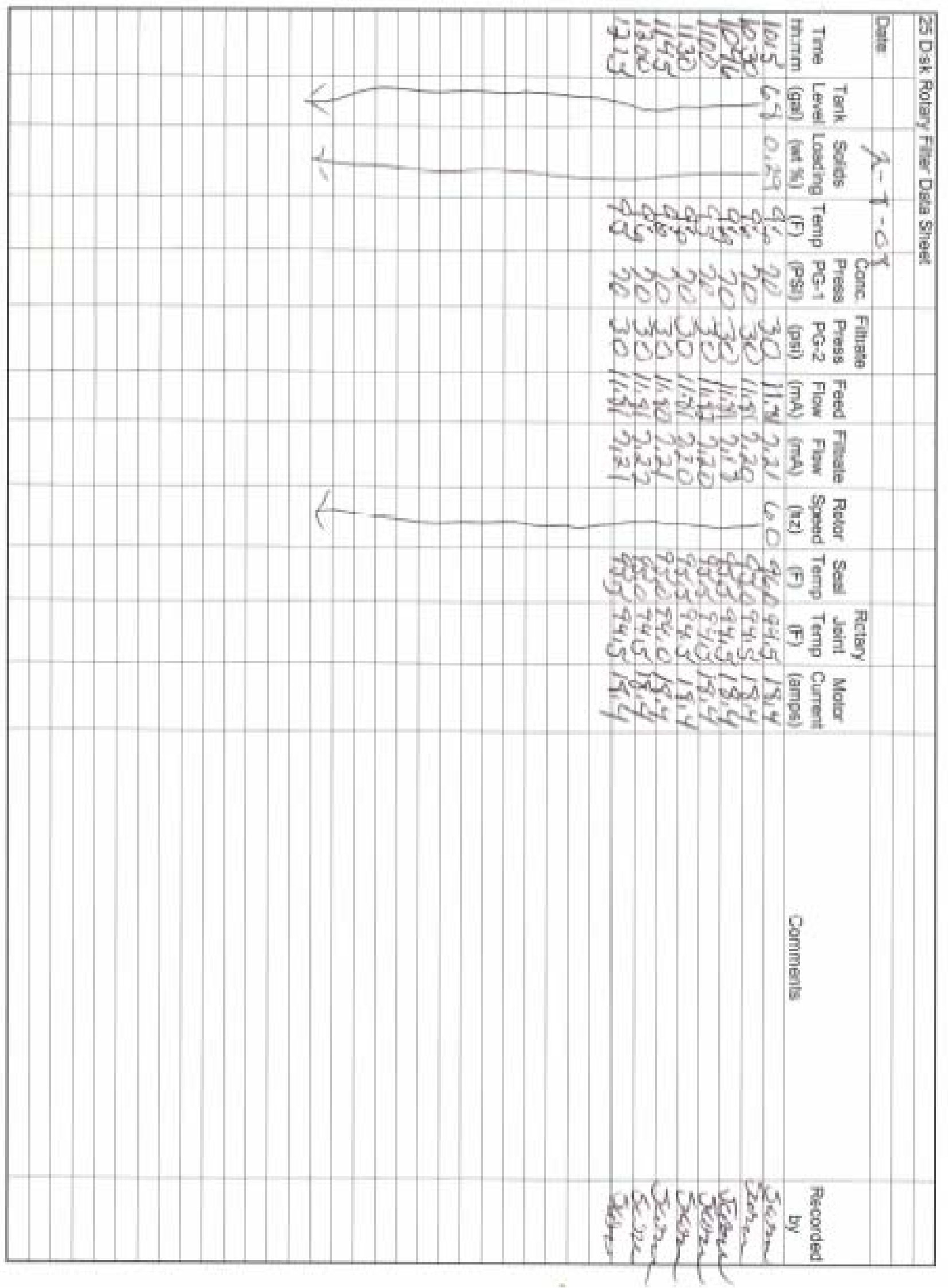


WSRC-STI-2008-00339

Revision 0

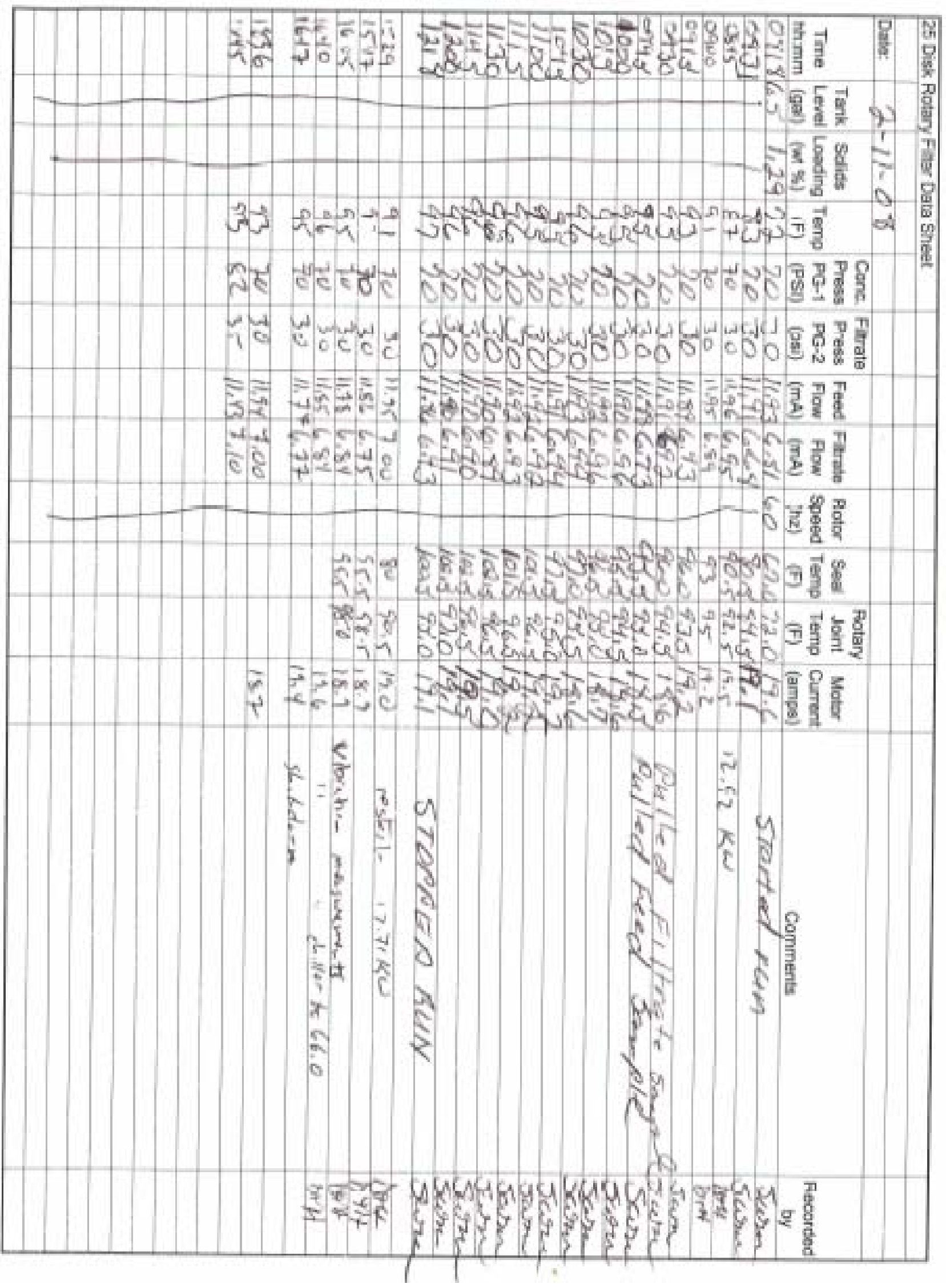


WSRC-STI-2008-00339

Revision 0

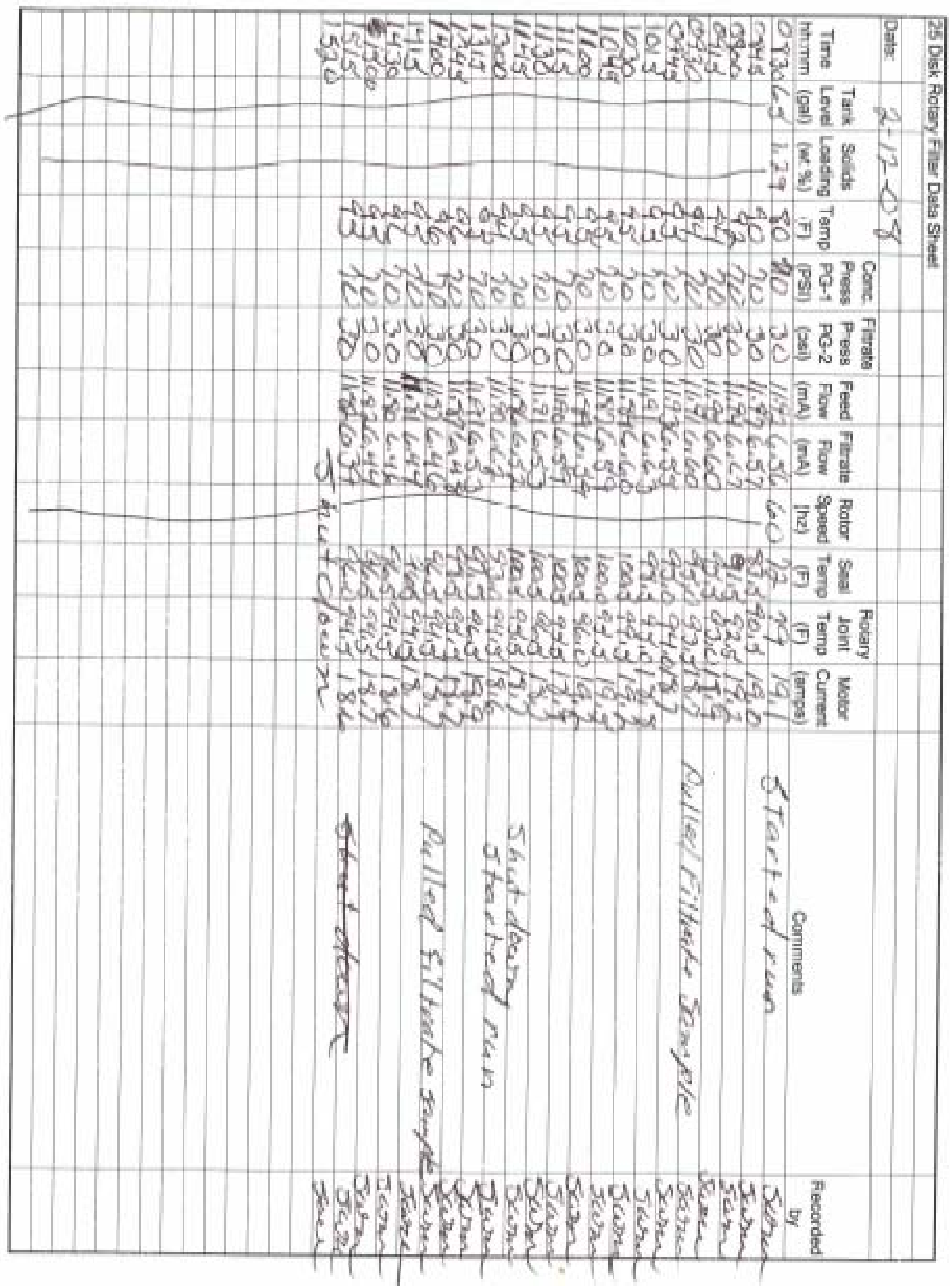


WSRC-STI-2008-00339

Revision 0

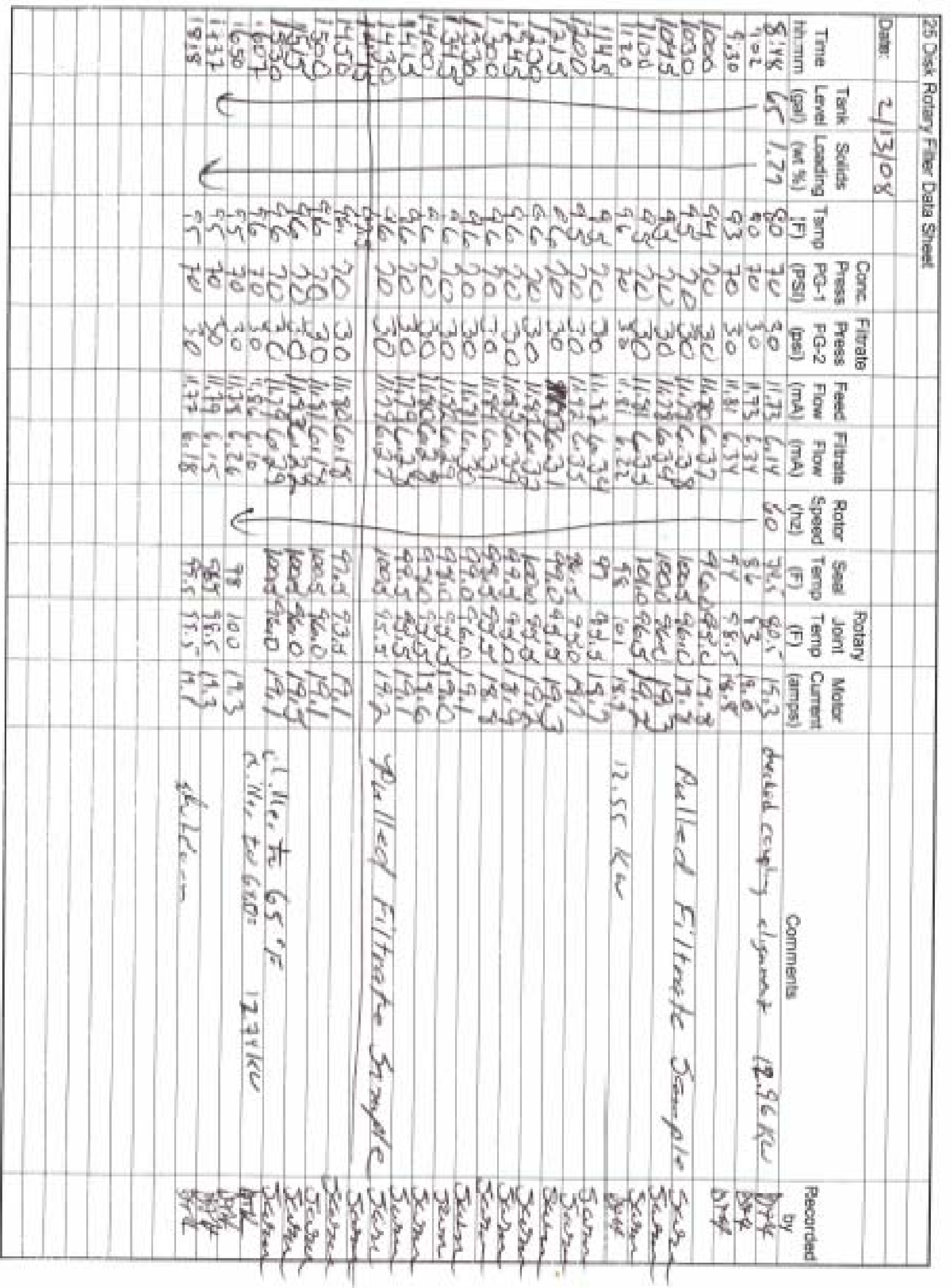


WSRC-STI-2008-00339

Revision 0

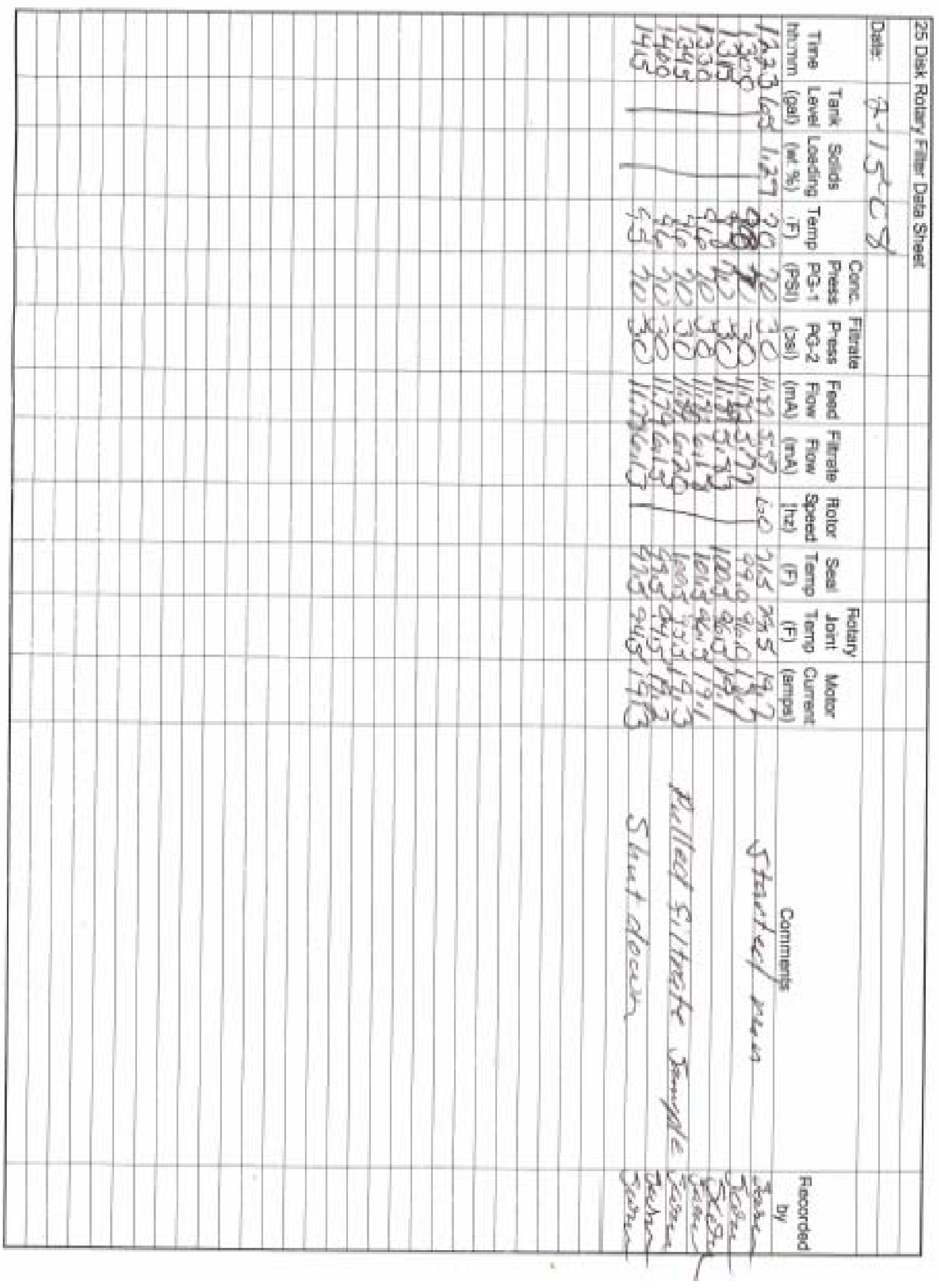


WSRC-STI-2008-00339

Revision 0

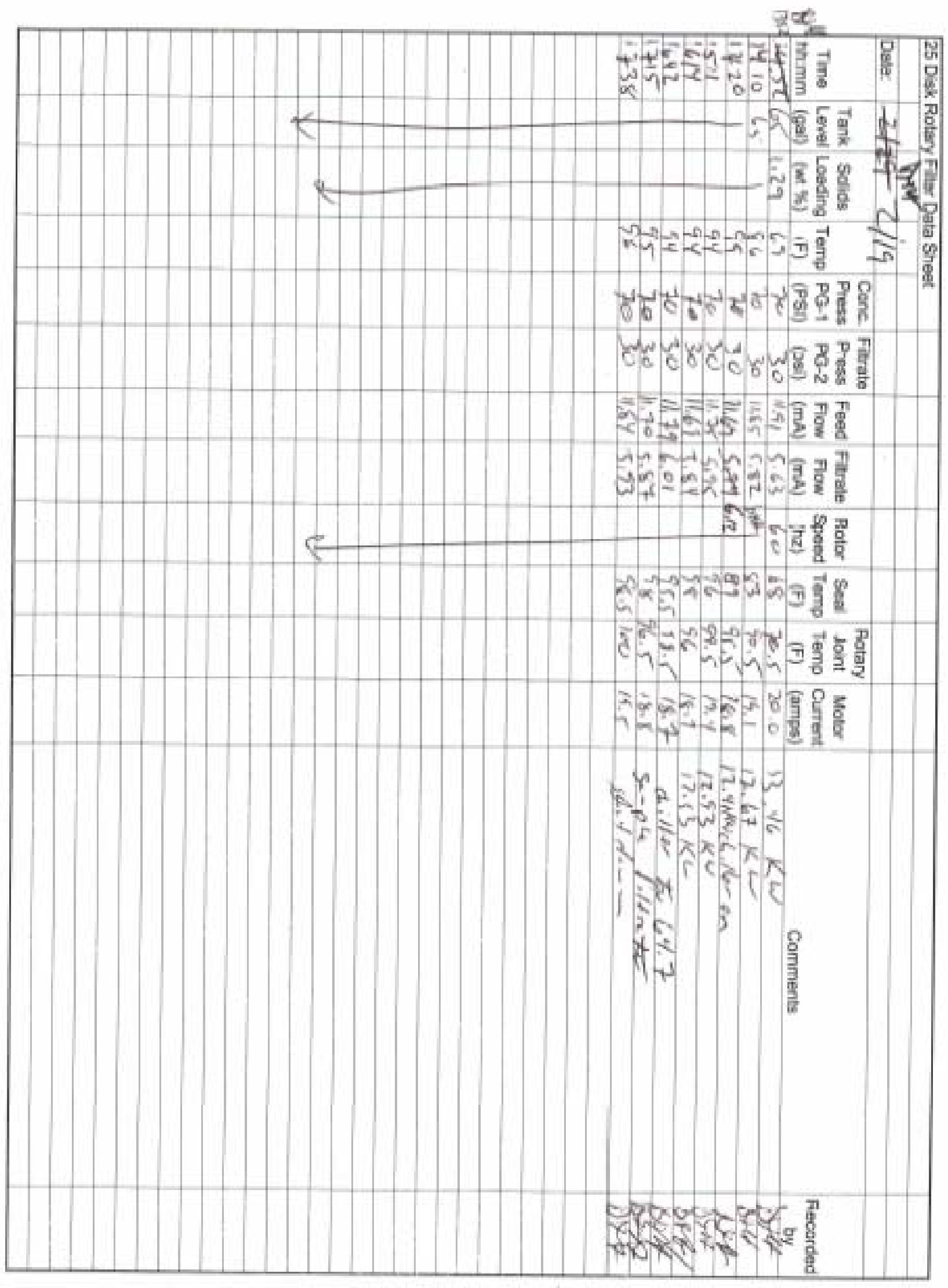


WSRC-STI-2008-00339

Revision 0

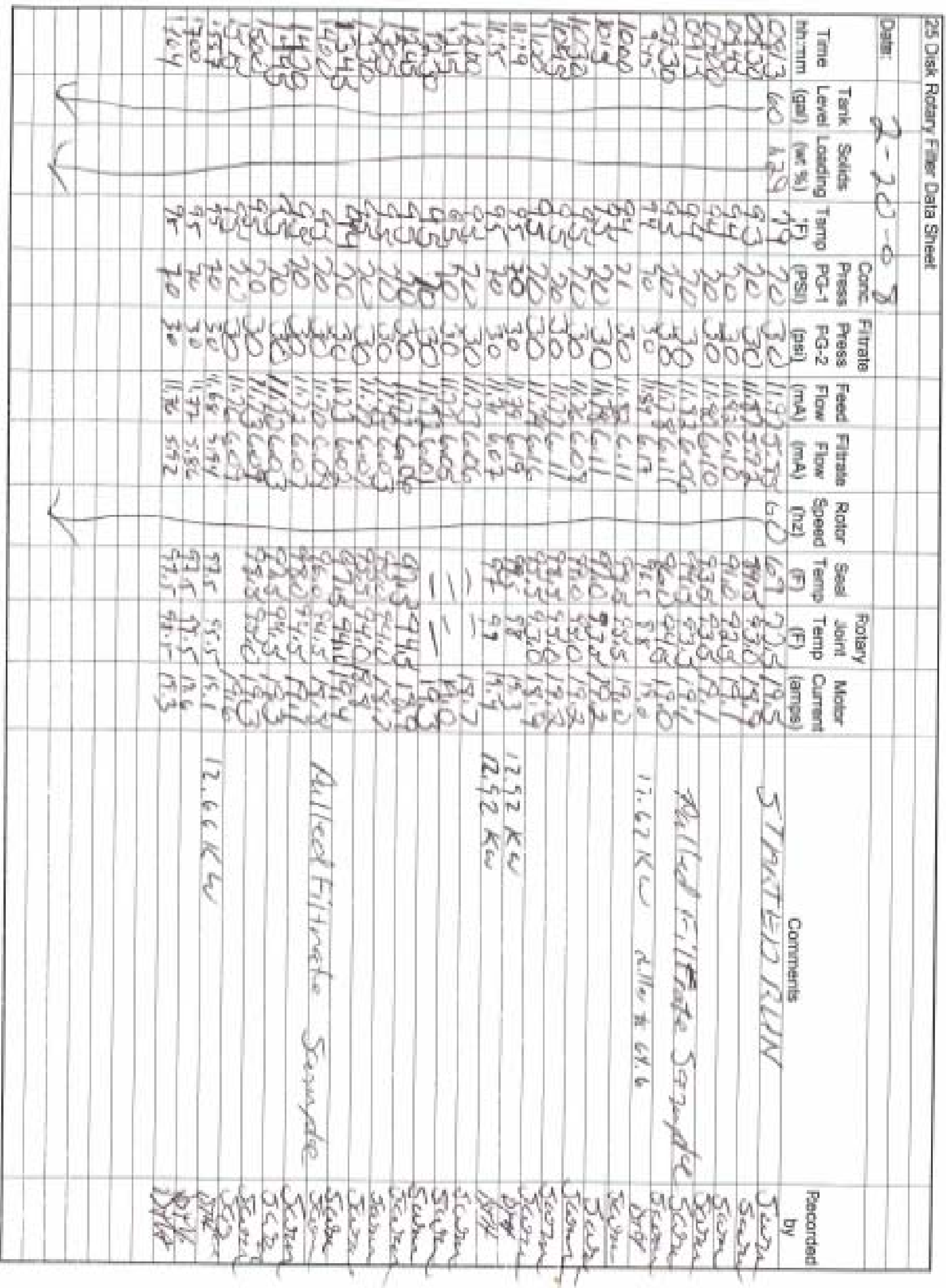


WSRC-STI-2008-00339

Revision 0

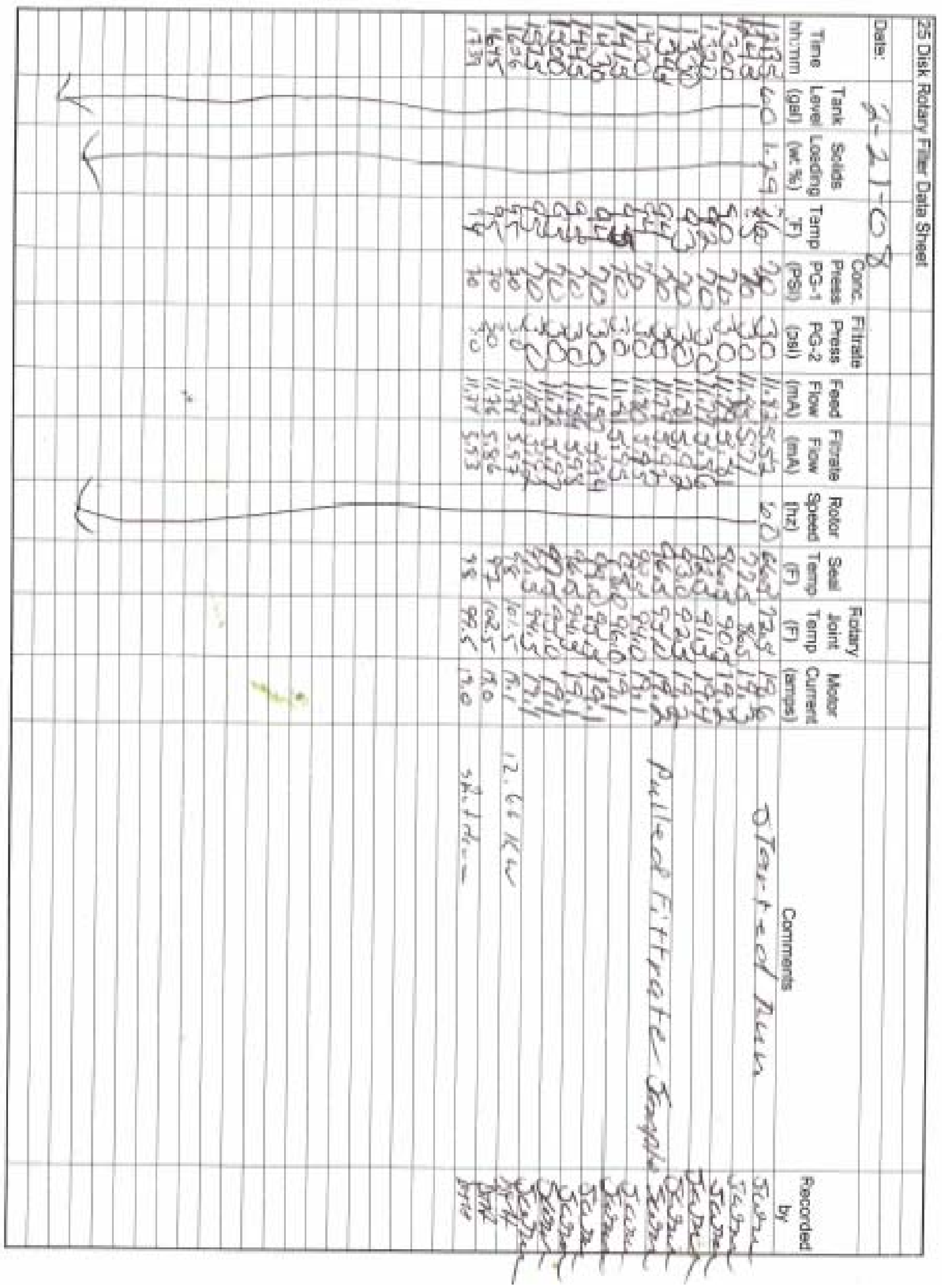


WSRC-STI-2008-00339

Revision 0

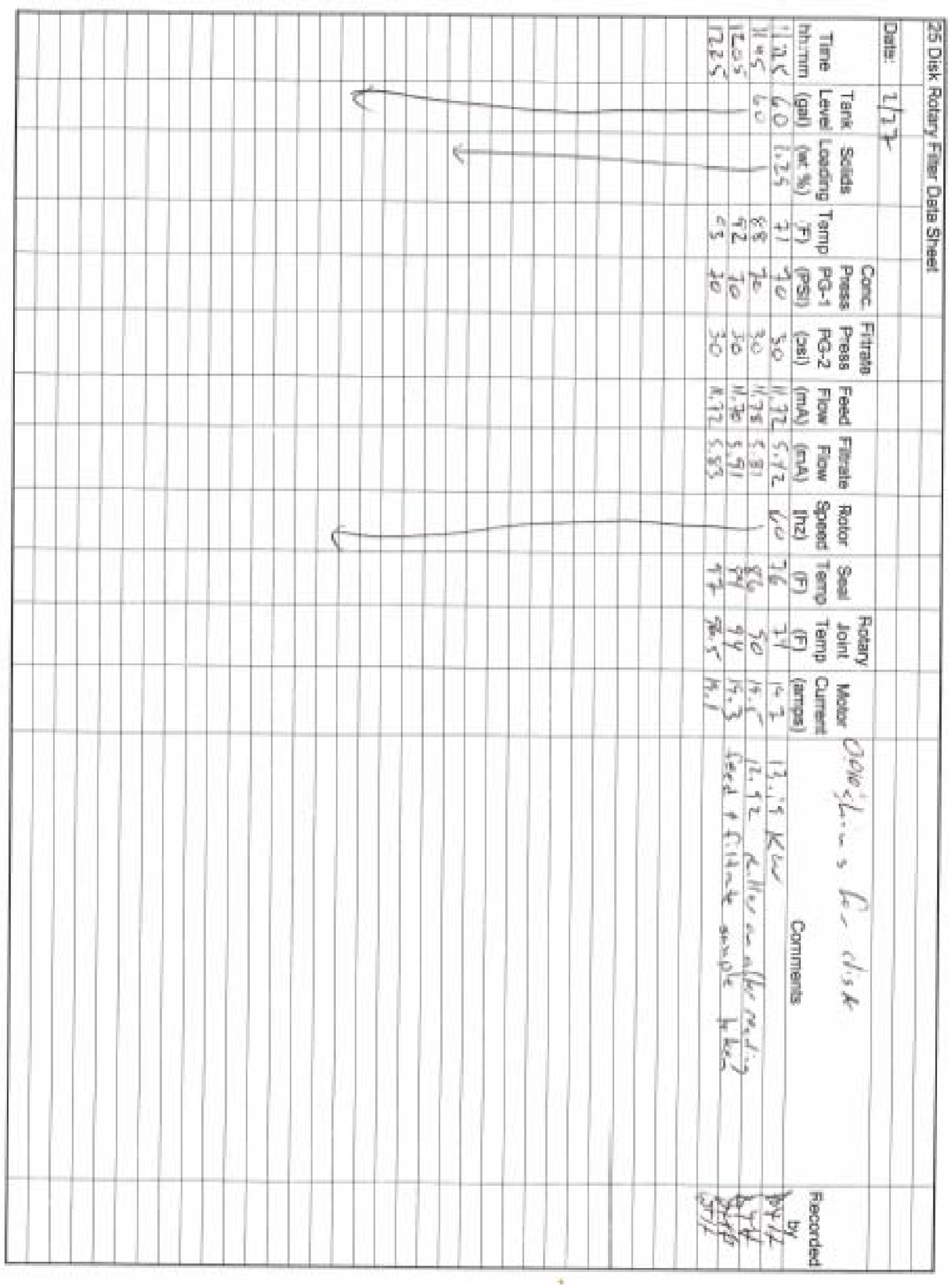


WSRC-STI-2008-00339

Revision 0

Appendix B: Solid Particles

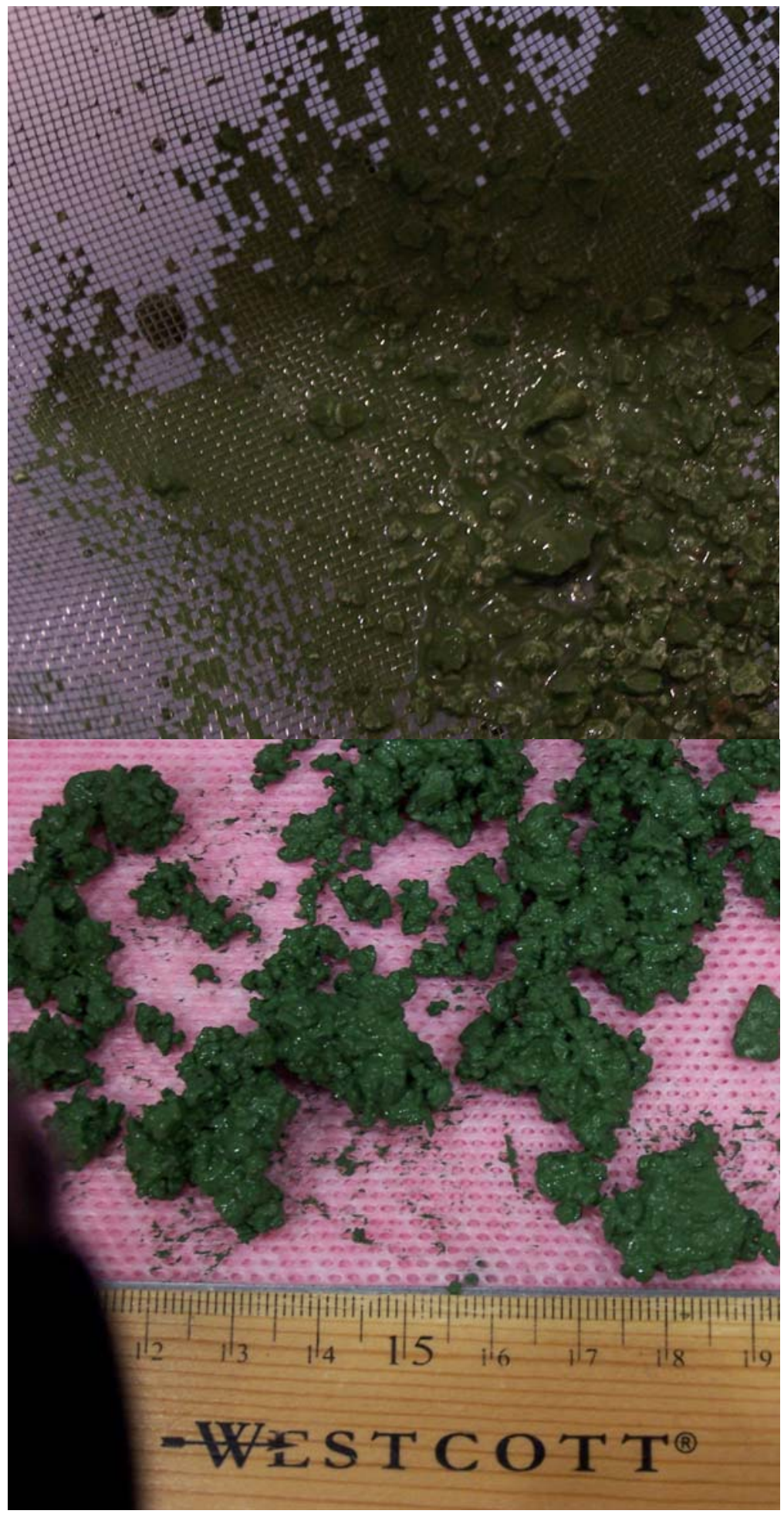

